\title{
SYSTEMATICS IN THE STRUCTURE AND XANES SPECTRA OF PYROXENES, AMPHIBOLES, AND MICAS AS DERIVED FROM ORIENTED SINGLE CRYSTALS
}

\author{
M. DARBY DYAR ${ }^{\S}$ \\ Department of Earth and Environment, Mount Holyoke College, 50 College Street, \\ South Hadley, Massachusetts 01075, U.S.A. \\ MICKEY E. GUNTER \\ Department of Geological Sciences, University of Idaho, Moscow, Idaho 83844-3022, U.S.A. \\ JEREMY S. DELANEY \\ Department of Geological Sciences, Wright Geological Laboratory, Busch Campus, Rutgers University, \\ Piscataway, New Jersey 08854, U.S.A.

\section{ANTONIo LANZAROTTI ANd STEPHEN R. SUTTON} \\ GSECARS and Department of Geophysical Sciences, 5640 South Ellis Avenue, Chicago, Illinois 60637, U.S.A.
}

\begin{abstract}
In order to assess the extent of X-ray anisotropy in biaxial minerals, Fe XANES spectra were acquired on single crystals of pyroxenes, amphiboles, and micas with the X-ray beam polarized along the X, Y, and Z optical orientations. Specifically, single crystals of enstatite (En), augite (Aug), aegirine (Ae), kaersutite (Krs; three different compositions), dioctahedral (Ms and Ill), and trioctahedral (Ann and Phl) micas were selected. Each crystal was oriented morphologically and with the aid of EXCALIBR using a spindle stage equipped polarized light microscope, and their XANES spectra were acquired at beamline X26a, NSLS, using a special geometry of the beam to accommodate the goniometer head and a $20 \times 30 \mu \mathrm{m}$ X-ray beam. As would be expected from visible and IR spectra of these minerals, the intensity of both pre-edge and main edge peaks is variable as a function of orientation. Structural similarities among these mineral groups result in similarities among their XANES spectra. Spectra acquired along the length of the chains ( $c$ for pyroxene, $c$ for amphibole, and $a$ for sheet silicates) are similar, with corresponding changes in the optical directions, such that $\mathrm{Y}_{\text {dioct }} \approx \mathrm{Z}_{\text {trioct }} \approx \mathrm{Z}_{\mathrm{Krs}} \approx \mathrm{Z}_{\mathrm{En}} \approx \mathrm{X}_{\mathrm{Ae}}$ (clinopyroxene is intermediate). Spectra taken along the $b$ crystallographic axes (along the layer of octahedra, across the I-beam) are similar for all groups $\left(\mathrm{Z}_{\text {dioct }} \approx \mathrm{Y}_{\text {trioct }} \approx \mathrm{Y}_{\mathrm{Krs}} \approx \mathrm{X}_{\mathrm{En}} \approx\right.$ $\mathrm{Y}_{\mathrm{Aug}}$ ), and more similar for the amphiboles and micas. Lastly, spectra acquired along the stacking direction, which is the $a$ crystallographic direction for pyroxene and amphiboles and the $c$ crystallographic direction in sheet silicates, are analogous. From these relationships, assignment of specific transitions to individual features in XANES spectra are facilitated. Furthermore, errors on use of pre-edge positions for determination of $\mathrm{Fe}^{3+} / \Sigma \mathrm{Fe}$ in minerals can be better constrained.
\end{abstract}

Keywords: XANES, XAS, single crystal, enstatite, augite, aegirine, kaersutite, annite, phlogopite, illite, muscovite, estimate of ferric iron.

\section{SOMMAIRE}

Afin d'évaluer le degré d'anisotropie aux rayons X dans les minéraux biaxiaux, nous avons acquis des spectres XANES à partir de cristaux uniques de pyroxènes, amphiboles, et micas en utilisant un faisceau de rayons $\mathrm{X}$ polarisé le long des directions optiques X, Y, et Z. Plus spécifiquement, des cristaux uniques d'enstatite (En), d'augite (Aug), d'aegyrine (Ae), de kaersutite (Krs; trois compositions différentes), mica dioctaédrique (Ms et Ill), et mica trioctaédrique (Ann et Phl) ont été choisis. Chaque cristal a été orienté selon sa morphologie et à l'aide du logiciel EXCALIBR en utilisant une platine à aiguille avec un microscope polarisant, et leurs spectres XANES ont été enregistrés au site NSLS avec le faisceau désigné X26a, avec un montage géométriquement spécialisé afin d'accommoder la tête du goniomètre dans le faisceau de rayons X de $20 \times 30 \mu \mathrm{m}$. Comme on

§ E-mail address: mdyar@mtholyoke.edu 
pourrait s'y attendre d'après les spectres de ces minéraux en lumière visible et infra-rouge, l'intensité des pics pré-seuil et seuil principal est variable selon l'orientation. Les ressemblances structurales parmi ces groupes de minéraux résultent de ressemblances dans les spectres XANES. Les spectres acquis le long des chaînes ( $c$ dans le cas de pyroxènes et des amphiboles, et $a$ dans le cas de silicates en feuillets) sont semblables, compte tenu des changements des directions optiques, de sorte que $\mathrm{Y}_{\text {dioct }} \approx \mathrm{Z}_{\text {trioct }} \approx \mathrm{Z}_{\mathrm{Krs}}$ $\approx \mathrm{Z}_{\mathrm{En}} \approx \mathrm{X}_{\mathrm{Ae}}$ (le clinopyroxène est intermédiaire). Les spectres prélevés le long de l'axe $b$ (le long de la couche d'octaèdres, transversalement aux modules en I) sont semblables pour tous les groupes $\left(\mathrm{Z}_{\mathrm{dioct}} \approx \mathrm{Y}_{\text {trioct }} \approx \mathrm{Y}_{\mathrm{Krs}} \approx \mathrm{X}_{\mathrm{En}} \approx \mathrm{Y}_{\text {Aug }}\right.$ ), et le sont davantage pour les amphiboles et les micas. Enfin, les spectres acquis le long de la direction d'empilement, le long de l'axe $a$ dans le cas des pyroxènes et des amphiboles et le long de l'axe $c$ dans le cas des silicates en feuillets, sont analogues. A partir de ces relations, l'attribution de transitions spécifiques à des aspects particuliers des spectres XANES s'en trouve facilitée. De plus, les erreurs dans l'application des positions pré-seuil pour déterminer le rapport $\mathrm{Fe}^{3+} / \Sigma \mathrm{Fe}$ dans les minéraux sont mieux controllées.

(Traduit par la Rédaction)

Mots-clés: spectre XANES, spectre, XAS, cristal unique, enstatite, augite, aegyrine, kaersutite, annite, phlogopite, illite, muscovite, estimation du fer ferrique.

\section{INTRODUCTION}

It is well known that biaxial minerals belonging to the orthorhombic, monoclinic, and triclinic systems display optical anisotropism, which is exhibited by different indices of refraction dependent on crystallographic directions. This phenomenon is related to optical pleochroism, which is the ability of minerals to transmit or absorb light of different wavelengths in different directions. This definition may be broadened to include not only visible light, but also waves with energies greater or less than those of visible light. For example, the indices of refraction of a mineral are controlled by absorption bands in the UV. More broadly, anisotropy in biaxial materials should be possible and expected at all wavelengths.

For the case of Fe $K$-XANES (X-Ray Absorption Near-Edge Structure) spectroscopy (ca. $7100 \mathrm{eV})$, anisotropy has rarely been characterized because of the time-consuming nature and difficulty in orienting small, single-crystal samples, as well as the rarity of microbeam synchrotron facilities. These problems can be overcome with an intense focused X-ray beam and the use of a spindle stage and methods developed by Bloss and coworkers (Bloss 1981, Gunter \& Twamley 2001) to orient single-crystal samples optically or by X-ray diffraction.

In this study, we examine the X-ray pleochroism of minerals in the structurally related pyroxene, amphibole, and mica groups. This paper is part of a larger program of study in which we examine X-ray pleochroism in a series of Fe-containing rock-forming minerals and relate it to the optical spectra of Co-bearing analogs. In the course of this work, systematics and inter-relationships of the XANES spectra among the pyroxenes, amphiboles, and sheet silicates became obvious. Thus, the goal of this study is to compare and contrast the structural similarities among these mineral groups and to relate them to their XANES spectra and optical orientations. From these relationships, a better understanding of the transitions represented by these spectra may ultimately be achieved, along with an improvement in use of these spectra for determination of $\mathrm{Fe}^{3+} / \Sigma \mathrm{Fe}$ in minerals.

\section{BACKGROUND}

As succinctly explained by Brown et al. (1988), the XANES region of an X-ray absorption spectrum consists of two parts defined by the relationship between the values of the incident photon energy, E, and the binding energy of a core-level electron, $\mathrm{E}_{\mathrm{b}}$, in the absorber. In the pre-edge region, $\mathrm{E}$ is less than $\mathrm{E}_{\mathrm{b}}$, so the electronic transitions are limited to low-probability localized transitions of the $K$-level $(1 s)$ electrons to the lowest-energy unoccupied or partially occupied levels. In the main-edge region, $\mathrm{E}$ is approximately equal to $E_{b}$, such that electronic transitions occur with a high probability from a core level $\left(E_{b}\right)$ to unoccupied bound states or continuum states (Brown et al. 1988). In this paper, the dependence of both sets of transitions on orientation will be considered.

\section{XANES main-edge spectra}

Until very recently, XANES spectra in this region, which begins $2-3 \mathrm{eV}$ above the pre-edge and continues to about $50 \mathrm{eV}$ above it, were impossible to interpret quantitatively. Features in this region represent superimposed contributions from multiple scattering interactions of the photoelectron and reflect both long-range and short-range order. Thus, the features are difficult to discriminate and assess quantitatively. Some progress in recognition of key features has been made through careful studies of micas with contrasting compositions; these are reviewed in detail in Mottana et al. (2002). For example, work by Mottana et al. (1997) on Al K edges showed that features corresponding to octahedrally and tetrahedrally coordinated Al could be distinguished in the XANES spectra of synthetic micas with compositions ranging from fluorine-substituted phlogopite to polylithionite. Next-nearest-neighbor effects also were characterized. Other valuable qualitative studies of the XANES region in mica spectra have been made 
by Manceau et al. (1998), Brigatti et al. (2001), Giuli et al. (2001), and Benfatto et al. (2001), and Tombolini et al. (2002), among others.

Although spectra of precisely oriented samples have not yet been published, orientation has been shown to have a strong effect on peak intensity in micas (Manceau et al. 1998, Dyar et al. 2001, Mottana et al. 2002). Unpublished data reported in the latter paper show that the best agreement between Fe XANES spectra for single crystal (at various angles) and homogeneous powder (grain size of $c a .5 \mu \mathrm{m}$ ) is obtained when the beam is polarized in a direction equal or very close to the "magic angle" value, $54.7^{\circ}$ (Pettifer et al. 1990, Stöhr 1992). The angle actually reflects the relatively high rotational symmetry $(>3)$ of the mica lattice in the basal plane, and provides a fundamental starting point for the determination of the magnitude of angle-dependent intensity for oriented slices such as those in a thin section. In other minerals, where rotational effects also are present, this angle may need to be modified to reflect the lower symmetry of the lattice.

For the beamline geometry used at the National Synchrotron Light Source X26a, the polarization of the incident X-ray beam is assumed to be almost perfectly linear in the plane of the ring. However, if the Kirkpatrick-Baez mirrors used to focus the X-ray beam alter the polarization characteristics of the beam so that it becomes elliptically polarized, then the dependence of the resonant signals measured from the sample on orientation may also change. The determination of the appropriate magic angle for making orientation-independent measurements will need to reflect that fact. In the work by Mottana and Manceau and coworkers, measurements in the transmission mode are used because they all employ powders and are geometrically simpler; this of course prevents the use of a microbeam for analysis of small single crystals.

\section{XANES pre-edge spectra}

The quantum mechanical rules of selection that control the transition probabilities in the pre-edge region are the same as those for optical phenomena (Brown et al. 1988), for which a theoretical and observational framework is already in place. Several different factors contribute to the intensity and peak energy of pre-edge features, including spin state, oxidation state, site geometry, and site symmetry. The $1 s \rightarrow \mathrm{n} d$ transitions in the pre-edge region are formally spin-forbidden, but they have non-zero transition probabilities owing to extremely weak electric quadrupole coupling (Hahn et al. 1982, Bair \& Goddard 1980, Brouder 1990). In cases where the cation occupies a noncentrosymmetric site, most of the intensity of the pre-edge features results from fundamentally intense electric dipole coupling between the $3 d$ and $4 p$ states (Randall et al. 1995, Roe et al. 1984, Westre et al. 1997). The amount of $4 p$ mixing into $\mathrm{Fe} 3 d$ orbitals is consistently larger for $\mathrm{Fe}^{3+}$ than for $\mathrm{Fe}^{2+}$ pre-edges. Westre et al. (1997) attributed this difference to the fact that bond lengths are shorter around $\mathrm{Fe}^{3+}$, and thus deviations from centrosymmetry are accentuated. The relatively symmetrical octahedral sites display little electric dipole coupling, but as site asymmetry increases, so does the $4 p$ mixing into $\mathrm{Fe} 3 d$ orbitals. Distortions from ideal symmetries of the octahedral to tetrahedral and square pyramidal geometries (as are found in most minerals) would tend to increase this mixing. So the pre-edge signal that is measured in most minerals probably represents the effect of asymmetry in the site and the dipolar effects associated with it. The transition probability (and thus the relative intensity of the peak) is increased if the number of "holes" in the $d$ orbitals is large. In general, pre-edge intensities are greater in $\mathrm{Fe}^{3+}$-bearing minerals because of the additional hole that is present in their ground state.

The position, or energy of the peaks, also is important, because it has a first-order relationship to oxidation state. As first explained by Shulman et al. (1976), XANES pre-edge transitions differ from their analogous optical transitions because the number of transitions present must be modeled for the $d^{(n+1)}$ excited state. So, the final state of any ion is best approximated by that of a different nucleus with atomic number $Z+1$ (Calas \& Petiau 1983, Shulman et al. 1976). XANES spectra will show the relative levels of energy that are predicted by the optical spectra for these $Z+1$ states.

For minerals in simple systems, theoretical pre-edge spectra can therefore be modeled on the basis of molecular orbital calculations that predict both intensity and energy of the component peaks. These calculations have been successfully done for numerous chemical compounds. For example, Randall et al. (1995) quantified the coordination number and symmetry of $\mathrm{Fe}^{2+}$ atoms in synthetic high-spin $\mathrm{Fe}^{2+}$ complexes, and Westre et al. (1997) used ligand-field theory to describe systematic relationships among spin state, oxidation state, and site geometry and the energy (i.e., position), splitting, and intensity distribution in a large variety of ferrous and ferric model compounds.

Because most rock-forming minerals are anisotropic, the effects of X-ray pleochroism that are introduced when studying mineral grains in thin section must also be considered. Dräger et al. (1988) were among the first to address the issue of the multipole character of the preedge in minerals. They used thin plates cut from oriented single crystals. They confirmed that isotropic samples show identical spectra when the polarization direction is either parallel or perpendicular to an oriented crystal. They also demonstrated that a conspicuous angular dependence of pre-edge absorption was found in the anisotropic (rhombohedral) minerals hematite and siderite. In hematite, for example, the intensity of a preedge peak at $7114 \mathrm{eV}$ is twice as intense with the beam parallel to (001) as it is with the beam perpendicular to (001). 


\section{DEtermination of $\mathrm{Fe}^{3+} / \Sigma \mathrm{Fe}$}

One of the most promising aspects of XANES spectroscopy is its potential for measuring $\mathrm{Fe}^{3+} / \Sigma \mathrm{Fe}$ at micrometer scales, an advance that would provide an attractive alternative to wet-chemical methods and Mössbauer spectroscopy. Because multiple scattering in the XANES main-edge region is so complex, efforts to measure $\mathrm{Fe}^{3+} / \Sigma \mathrm{Fe}$ have focused instead on the pre-edge region. One of the first major advances in this field was made by Bajt et al. (1994), who used a calibration method based on Gaussian line-shape fits to single peaks for each pre-edge. The resultant pre-edge peak energies from synthetic fayalite $\left(\mathrm{Fe}_{2} \mathrm{SiO}_{4}, 0 \% \mathrm{Fe}^{3+}\right)$, natural magnetite $\left(\mathrm{Fe}_{3} \mathrm{O}_{4}, 66.7 \% \mathrm{Fe}^{3+}\right)$, and hematite $\left(\mathrm{Fe}_{2} \mathrm{O}_{3}, 100 \%\right.$ $\left.\mathrm{Fe}^{3+}\right)$ are used to derive a calibration line for the determination of $\mathrm{Fe}^{3+}$ content from pre-edge energy. This method has permitted reasonably successful measurements of $\mathrm{Fe}^{3+} / \Sigma \mathrm{Fe}$ in garnets, olivines, pyroxenes, amphiboles, micas, tourmalines, feldspars, and other minerals and glasses in an array of terrestrial materials (Delaney et al. 1998). However, it yields results with large errors ( $\pm 5-15 \%$ based on replicate analyses) for at least three main reasons: 1) The geometry of the Fe sites in fayalite, magnetite, and hematite is commonly dissimilar to that of the unknowns, and therefore peak energies and intensities in the unknowns differ from those in the standards. 2) Use of the pre-edge centroid is an oversimplification because the pre-edges themselves are composed of several different peaks, the multiplicity of which is predicted by crystal-field theory. 3) The measurements are commonly made on minerals in thin sections, for which the poorly known crystallographic orientation of the grain is problematic.

The first two issues have largely been addressed in recent work by Galoisy et al. (2001) and Wilke et al. (2001). In the former study, single mineral species were chosen to represent each type of Fe valence and coordination. Reference spectra of andradite are used for ${ }^{[6]} \mathrm{Fe}^{3+}$, glass of augite composition for ${ }^{[4,5]} \mathrm{Fe}^{2+}$, berlinite for ${ }^{[4]} \mathrm{Fe}^{3+}$, staurolite for ${ }^{[4]} \mathrm{Fe}^{2+}$, and siderite for ${ }^{[6]} \mathrm{Fe}^{2+}$. Multiple pseudo-Voigt line shapes (in most cases) were used to deconvolute the pre-edge spectra into two to four peaks each, and then spectra of unknowns were fit to linear combinations of the pure reference spectra. Errors on resultant $\mathrm{Fe}^{3+} / \Sigma \mathrm{Fe}$ were reported to be $\pm 10 \%$, and discrepancies were attributed to the method for numerically extracting the pre-edge from the main edge, and to differences in site geometry between their references and the unknown minerals.

Wilke et al. (2001) and Petit et al. (2001) expanded upon this approach; they characterized and fit 35 minerals and synthetic compounds in order to correlate characteristics of pre-edge features with oxidation state and local coordination environments. Their results also showed that $\mathrm{Fe}^{3+}$ contents of minerals can be determined with an accuracy of $\pm 10 \mathrm{~mol} \%$, provided that the site geometry for each $\mathrm{Fe}$ atom in the structure is known.
However, Galoisy et al. (2001), Wilke et al. (2001), and Petit et al. (2001) used powdered samples. Although their work is important because it demonstrates the utility of interpreting XANES pre-edges for $\mathrm{Fe}^{3+} / \Sigma \mathrm{Fe}$, it only adds to the existing methods for analysis of $\mathrm{Fe}^{3+} /$ $\Sigma$ Fe in powdered samples.

From a geologist's perspective, the more tantalizing prospect is to advance the use of this method for analysis of minerals in thin section or as small single crystals. In order to completely understand the orientation effects that will hinder the analysis in thin section of $\mathrm{Fe}^{3+} / \Sigma \mathrm{Fe}$, it will be necessary to examine (and fit with pseudo-Voigt components) pre-edge spectra acquired at each of the optical orientations in each of the end-member model compounds using spherical samples, low Fecompositions, and high-resolution monochromators.

In the present paper, we consider only the effects of orientation on the centroid of the pre-edge features, as these are currently used in (admittedly simplistic) determination of $\mathrm{Fe}^{3+} / \Sigma \mathrm{Fe}$ of minerals in thin sections (Dyar et al. 2002). We recognize that in the long term, use of $\mathrm{Fe}^{2+}$ and $\mathrm{Fe}^{3+}$ end-member model compounds coupled with knowledge of crystal orientation (both in the standards and the unknowns) will be necessary to achieve the most accurate estimates of $\mathrm{Fe}^{3+} / \Sigma \mathrm{Fe}$ of minerals in thin section.

\section{Methods}

\section{Samples studied}

Samples used in this study were obtained from the collections of the authors (MDD and JSD) and localities are listed in Table 1; chemical compositions for all samples are reported in Table 2. With the exception of the Serra de Magé enstatite of meteoritic origin, for which insufficient sample was available, the samples have been previously studied by MDD using Mössbauer spectroscopy; they were chosen to represent a range of mineral structures and $\mathrm{Fe}^{3+} / \Sigma \mathrm{Fe}$ contents. In many cases, sample selection was further constrained by the need for inclusion-free, untwinned single crystals with sizes exceeding $30 \mu \mathrm{m}$ (at least in one dimension).

Single crystals were oriented morphologically and with the aid of EXCALIBR (Gunter \& Twamley 2001) by MEG using a spindle-stage-equipped polarized light microscope. The optical orientations of all the samples were either checked morphologically or determined on the basis of methods discussed in Gunter \& Twamley (2001). Once oriented, the twelve samples listed in Table 1 were first photographed (for example, Fig. 1), and then the twelve goniometer heads were carefully packed and hand-carried to NSLS by MEG.

In this paper, we refer to $\mathrm{X}, \mathrm{Y}$, and $\mathrm{Z}$ optical directions, which are the three mutually perpendicular vectors that describe the biaxial indicatrix. $\mathrm{X}$ and $\mathrm{Z}$ always correspond to the directions that exhibit indices of refraction $\alpha$ and $\gamma$, respectively. Then $\beta$ corresponds not 
only to the $\mathrm{Y}$ direction, which is perpendicular to $\mathrm{X}$ and $\mathrm{Z}$, but also to an infinite number of vectors of the same length located in the two circular sections of the biaxial

TABLE 1. SAMPLES STUDED

\begin{tabular}{lll}
\hline Mineral nane Symbol Locality & Citation \\
\hline
\end{tabular}

\section{Pytoremes}

\begin{tabular}{|c|c|c|c|}
\hline $\begin{array}{l}\text { Serta de Magd } \\
\text { cristatite SdM }\end{array}$ & En & $\begin{array}{l}\text { Setre de Mage erotite, } \\
\text { collection of AMllyH }\end{array}$ & Harlow et al (1979) \\
\hline \multicolumn{3}{|l|}{ DH-200 } & Dyar et orl (1996) \\
\hline Aegir aegirine & Ae & $\begin{array}{l}\text { Rundemyr, Eker, maf } \\
\text { Kongiberg. Bugkesud, } \\
\text { Norway }\end{array}$ & Berzelins (1835) \\
\hline \multicolumn{4}{|c|}{ Amphibutes } \\
\hline $\begin{array}{l}\text { katsutite } \\
\text { AK-MR }\end{array}$ & $\mathbf{K} \mathbf{s}$ & $\begin{array}{l}\text { Harrat al Kishl, } \\
\text { Saudi Asabia } \\
\text { Colemun localily H2? I }\end{array}$ & Dyar ef at. (1993) \\
\hline $\begin{array}{l}\text { knersutite } \\
\text { FR-12 }\end{array}$ & $\mathrm{Krs}$ & $\begin{array}{l}\text { Massif Gentral, Montgros, } \\
\text { France }\end{array}$ & Dyar at al (1993) \\
\hline $\begin{array}{l}\text { Jastsutite } \\
\text { Tm }\end{array}$ & Krs & $\begin{array}{l}\text { Easy Chair Crates, Lunar } \\
\text { Erater, Newada }\end{array}$ & Dyar el al (1993) \\
\hline \multicolumn{4}{|c|}{ Triontahedral míces } \\
\hline $\begin{array}{l}\text { phlogopite } \\
\text { O-H-49 }\end{array}$ & Phl & $\begin{array}{l}\text { Oquossce quadrangle, } \\
\text { western Maine }\end{array}$ & Guidatti \& Dyar (1991) \\
\hline & Arti & Pikes Feak, Coloredo & Dyar tef af (2001) \\
\hline $\begin{array}{l}\text { phlogopite } \\
\text { synthetic }\end{array}$ & Fhl & $\begin{array}{l}\text { sythetic sample courtesy } \\
\text { of } R \text {. Hazen }\end{array}$ & Dyar es al (2001) \\
\hline \multicolumn{4}{|c|}{ Bioctuhedral micht } \\
\hline $\begin{array}{l}\text { illite } \\
\text { ATL-34 }\end{array}$ & [1] & $\begin{array}{l}\text { Atloy islard, Sutriford, Sogr } \\
\text { ge Fjordlane fylke, Norway }\end{array}$ & Andersen et al. (1998) \\
\hline $\begin{array}{l}\text { illine } \\
\text { ATL-15 }\end{array}$ & [1] & $\begin{array}{l}\text { Alley island, Sutrijord, Sogn } \\
\text { og Fjordlane fylke, Norway }\end{array}$ & Atudersen et al. (1998) \\
\hline $\begin{array}{l}\text { muscosite } \\
\text { SBG-83 }\end{array}$ & $\mathrm{Ms}$ & Sebago barholith, Maine & Guidetti af a. (1994) \\
\hline
\end{tabular}

indicatrix ( $c f$. Fig. 3.8, Bloss 1981). Thus $\beta$, though often used to define the $\mathrm{Y}$ direction, defines an infinite number of directions in a biaxial indicatrix. In the analogous literature on optical spectroscopy, $\alpha, \beta$, and $\gamma$ are often used to refer to $\mathrm{X}, \mathrm{Y}$, and $\mathrm{Z}$.

Samples were oriented along optical $(X, Y, Z)$ rather than crystallographic $(a, b, c)$ directions because we wished to compare these XANES spectra to other optical spectra that are traditionally collected along optical orientations. This choice may seem to lead to complicated relationships based on changing optical orientations among these mineral groups (see Discussion). However, collecting the data along $a, b$, and $c$ would have presented a similar set of problems because the crystallographic axes in the monoclinic crystal systems are not orthogonal, and in turn would make comparisons difficult between, say, orthopyroxenes and clinopyroxenes.

\section{XANES measurements}

XANES measurements were made at the synchrotron X-ray microprobe (beamline X26a at the National Synchrotron Light Source, Brookhaven National Laboratory, Upton, N.Y.). A special geometry of the beam was used (Fig. 2; see also Dyar et al. 2002). On the beamline, a spindle stage was mounted with one plane of rotation perpendicular to the path of the beam. This geometry is similar to that used in normal spindle-stage measurements when the spindle stage is mounted onto a microscope stage (Bloss 1981, Gunter \& Twamley 2001). This geometry allowed spectra to be acquired with the beam polarized directly parallel to the X, Y, and $\mathrm{Z}$ optical directions, or any other direction of choice.

The structure of the Fe $K$ absorption edge was scanned in the near-edge region. Incident beam ener-

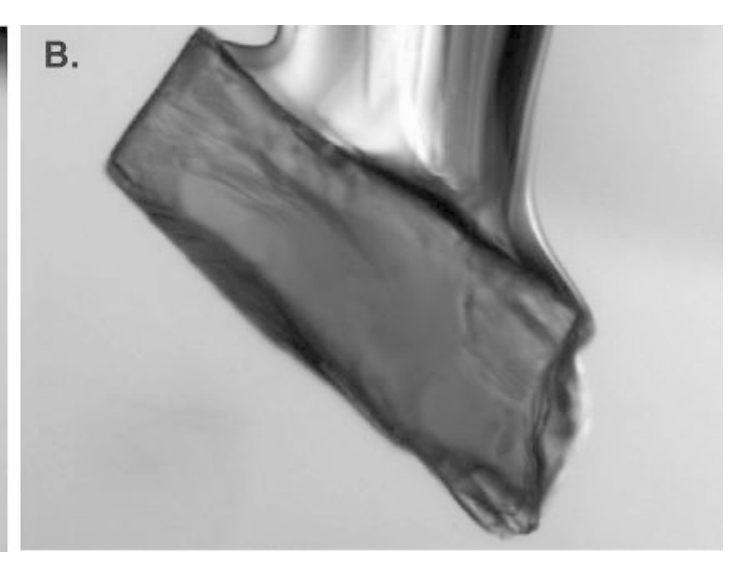

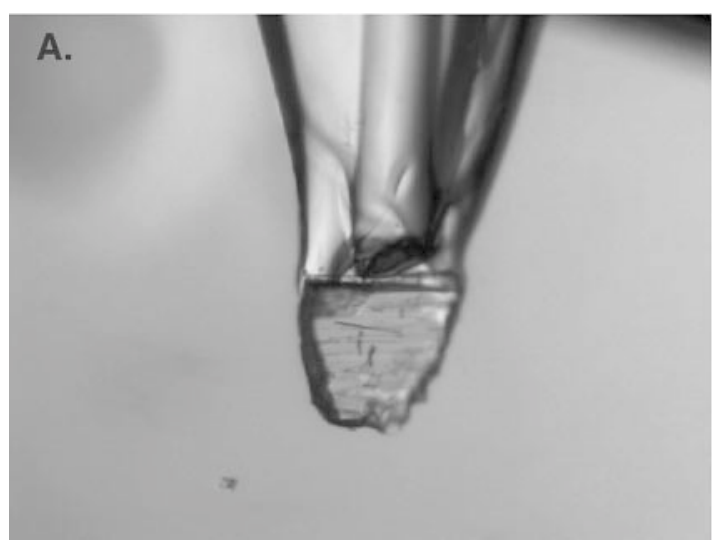

FIG. 1. Photomicrographs of single crystals mounted on the end of glass fibers with clear fingernail polish and immersed in index of refraction liquid. Approximate diameter of fibers is $50 \mu \mathrm{m}$. (A) Enstatite from the Serra de Magé meteorite. (B) Augite from Dish Hill, California. 
gies from $50 \mathrm{eV}$ below the main energy of the absorption edge (7111 eV for $\mathrm{Fe}$ ) to about $60 \mathrm{eV}$ above the main edge were used. The beam was positioned to strike an oriented edge of a razor blade so that the beam position could be constrained to within $<5-15 \mu \mathrm{m}$. Using mutually orthogonal Kirkpatrick-Baez mirrors, the beam was focused to a $c a .20 \times 30 \mu \mathrm{m}$ size for the single crystals. The X-ray sampling depth is large, but $>90 \%$ of the signal comes from the top $10 \mu \mathrm{m}$ of the sample. The energy of the incident beam was controlled by a $\mathrm{Si}(111)$ channel-cut monochromator. The energy of the incident X-ray beam was incremented by $0.3 \mathrm{eV}$ intervals over the most critical range in energy, -10 to $+20 \mathrm{eV}$, relative to the energy of the main absorption. This strategy provides detailed mapping of the relationship between the pre-edge peak and the main absorption edge for comparison with the magnetite standard (see below), for which the pre-edge position is arbitrarily defined as $0.0 \mathrm{eV}$. Between -50 and $-10 \mathrm{eV}$ and above $+20 \mathrm{eV}$, the $\mathrm{X}$-ray energy was incremented by

TABLE 2. MINERAL COMPOSITIONS

\begin{tabular}{|c|c|c|c|c|c|c|c|c|c|c|c|c|}
\hline & $\begin{array}{c}E_{n} \\
\text { SdM' }\end{array}$ & $\begin{array}{l}\text { Av! } \\
\text { DH- } \\
209^{2}\end{array}$ & $\begin{array}{c}\text { Afe } \\
\text { Aegir }\end{array}$ & $\begin{array}{l}\text { Krs } \\
A K- \\
M 2^{4}\end{array}$ & $\begin{array}{l}\mathrm{KF} \\
\mathrm{FR}- \\
12^{4}\end{array}$ & $\begin{array}{l}\text { Krs } \\
\text { Tm" }\end{array}$ & $\begin{array}{l}\mathrm{Ann} \\
\mathrm{PP}^{3}\end{array}$ & $\begin{array}{c}\text { Phl } \\
\mathrm{O}-\mathrm{H} \\
-49^{15}\end{array}$ & $\begin{array}{c}\text { Pht } \\
\text { Syri- } \\
\text { theticis }^{3}\end{array}$ & $\begin{array}{c}\text { Ill } \\
\text { ATL- } \\
34^{6}\end{array}$ & $\underset{35^{6}}{\text { Ill }}$ & $\begin{array}{c}\mathrm{Ms} \\
\text { SBG- } \\
83^{\top}\end{array}$ \\
\hline $\mathrm{SiO}_{2} \mathrm{w} \%$ & 52,30 & 50.89 & 52.39 & 39.93 & 39.29 & 40.05 & 33.87 & 35.49 & 40.99 & 47.20 & 48.05 & 46.89 \\
\hline $\mathrm{M}_{2} \mathrm{O}_{\mathrm{k}}$ & 0.34 & 6.64 & 0.36 & 14.83 & 13.85 & 14.48 & 11.56 & 19.32 & 8.93 & 25.97 & 28.61 & 34.75 \\
\hline $\mathrm{TiO}_{2}$ & 0.24 & 0.70 & 1.29 & 5.31 & 3.27 & 4.49 & $3.3 \overline{8}$ & 1.78 & 0,14 & 108 & 095 & 0.58 \\
\hline Feo & 27.40 & 4.43 & 0.00 & 8.24 & 0.00 & 3.00 & 32.37 & 14.76 & 3.95 & 2.01 & 2.16 & 1.56 \\
\hline $\mathrm{Fe}_{3} \mathrm{O}_{\mathrm{k}}$ & 0.00 & 1.17 & 31.45 & 3.10 & $1] .68$ & 10.98 & 4.45 & 4.90 & 7.17 & 6.64 & 2.92 & 0.81 \\
\hline $\mathrm{Cr}_{3} \mathrm{O}$ & 0.12 & $0.5 ?$ & & 0,02 & 0.02 & 0.02 & & & & & & \\
\hline $\mathrm{MgO}$ & 18.60 & 17.11 & 0.22 & 12.84 & 13.77 & 11.92 & 1.05 & 9.93 & 24.01 & 2.63 & 3.09 & 0.88 \\
\hline $\mathrm{MnO}$ & 0.95 & 0.15 & 0.62 & 009 & 010 & 0.12 & 0.55 & 0.24 & 0.03 & $0.0 \mathrm{I}$ & 0.02 & 0.05 \\
\hline $\mathrm{ZnO}$ & & & & 0.00 & 000 & 0.00 & & 0.08 & & 0.03 & 0,03 & 0.60 \\
\hline $\mathrm{CaO}$ & 0.75 & 18.44 & 0.29 & 987 & 12.10 & 10.73 & 0.00 & 0.00 & 0.00 & 0.00 & 0,00 & 0,00 \\
\hline $\mathrm{Na}_{2} \mathrm{O}$ & & 0.95 & 13.18 & 2.91 & 1.96 & 273 & 007 & 0.25 & 0.09 & 0.08 & 0.11 & 0.16 \\
\hline $\mathrm{K}_{2} \mathrm{O}$ & & 0.00 & 0.02 & 1.10 & 2.18 & 1.35 & 8.72 & 8.97 & 10.31 & 7.87 & 7.65 & 10.55 \\
\hline Ba & & & & 0,00 & 0,00 & 000 & & 0.12 & & 0.16 & 0.40 & 0.01 \\
\hline$F$ & & 0.03 & & 0.00 & 0.60 & 0.00 & 0.99 & 0.41 & 0.57 & 0.00 & 0.05 & 0.21 \\
\hline $\mathrm{Cl}$ & & 0.00 & & 0.00 & 0.00 & 0.00 & 0.44 & 0.00 & 0,01 & 0,00 & 0.00 & 0.06 \\
\hline $\mathrm{H}_{2} \mathrm{O}$ & & 0.16 & & 1.03 & 0.17 & 0.07 & 2.41 & 375 & 4.14 & 4.26 & 4.03 & 3.63 \\
\hline Sum & 100.70 & 101.24 & 99.82 & $99.27 \quad 9$ & 98.39 & 99.94 & 99,8610 & 00,00110 & $0,3,34$ & 97.94 & $98.05 \mathrm{~J}$ & 100.14 \\
\hline HO & 6 & 6 & 6 & 24 & 24 & 24 & 12 & 12 & 12 & 12 & 12 & 12 \\
\hline Si $a p f u$ & 1.987 & 1.827 & 2.005 & 5.944 & 5945 & 5.990 & 2843 & 2.663 & 2.953 & 3.247 & 3.267 & 3.143 \\
\hline Al & 0.015 & 0.281 & 0.016 & 2.602 & 2.470 & 2.532 & 1,143 & 1.709 & 0.758 & 2.106 & 2.292 & 2.745 \\
\hline $\mathrm{Ti}$ & 0.018 & 0.053 & 0.097 & 1.595 & 0.982 & 1.349 & 0,508 & 0.267 & 0.021 & 0.152 & 0.143 & 0.087 \\
\hline $\mathrm{Fe}^{1-}$ & 0.870 & 0.133 & 0.000 & 1,026 & 0,0000 & 0.375 & 2.272 & 0.926 & 0238 & 0.116 & 0.123 & 0.087 \\
\hline $\mathrm{Fe}^{3+}$ & 0.000 & 0.032 & 0.906 & 0.347 & 1,330 & 1,236 & 0.281 & 0.277 & 0.389 & 0.344 & 0.149 & 0.041 \\
\hline Cr & 0.004 & 0.016 & 0.000 & 0.002 & 0,002 & 0.002 & & & & & & \\
\hline $\mathrm{Mg}$ & 1.053 & 0.915 & 0.013 & 2,849 & 3,105 & 2.657 & 0.131 & 1.111 & 2.578 & 0.270 & 0,313 & 0.088 \\
\hline $\mathrm{Mn}$ & 0.031 & 0.005 & 0,020 & $0,0 \mathrm{il}$ & 0.013 & 0.015 & 0.039 & 0.015 & 0.002 & 0,001 & 0,001 & 0.003 \\
\hline $2 n$ & & & & 0,500 & 0.500 & 0.000 & & 0.004 & & 0.002 & 0.002 & 0.000 \\
\hline $\mathrm{Ca}$ & 0.031 & 0.709 & 0.012 & 1.574 & 1.961 & 1.719 & 0.000 & 0.000 & 0.000 & 0.000 & 0000 & 0.000 \\
\hline $\mathrm{Na}$ & & 0.066 & 0.978 & 0.840 & 0.575 & 0.792 & 0.011 & 0.035 & 0.013 & 0.111 & 0014 & 0.021 \\
\hline $\mathbf{K}$ & & 0.000 & 0.001 & 0.209 & 0.421 & 0.258 & 0.934 & 0.859 & 0.948 & 0.691 & 0.662 & 0.902 \\
\hline $\mathrm{Ba}$ & & & & 0.000 & 0.000 & 0.000 & & 0.004 & & 0.004 & 0.011 & 0.000 \\
\hline$E$ & & 0,003 & & 0.000 & 0.000 & 0.500 & 0.263 & 0.097 & 0.130 & 0.000 & 0.011 & 0.045 \\
\hline $\mathrm{Cl}$ & & 0,000 & & 0.000 & 0.000 & 0.600 & 0.063 & 0.000 & 0.001 & 0.000 & 0.000 & 0.007 \\
\hline $\mathrm{H}$ & & 0.038 & & 1.022 & 0.172 & 0.070 & 1.349 & 1.877 & 1989 & 1.954 & 1.827 & 1.622 \\
\hline
\end{tabular}

${ }^{3}$ Data from Harlow er al. (1979) ${ }^{2}$ Data from Dyar at al. (1996) * Unpublished results of EPMA analyses done at Rutgers University, Data were collected with a JEOL JXA-8600 Superprobe with Tracor Northern/Noran 5600 Series It autonation package. Dperating conditions: accelerating voltage $20 \mathrm{kV}$, bean current in Faraday cup 20 uA, with continuously rastered beam on 5-10 km spet. The data were cotuected using $Z A F$ procedures. " Data from Dyar el al. (1993). "Data from Guidotti \& Dyar (1991). " Uapublished results of EPMA analyses at the University of Maine. Data were collected with an ARL-SEMQ electron microprobe eutomated with Advanced Microbean lnc, Micto 3 WD automation package. Operating conditions accelerating voltage $15 \mathrm{kV}$, beam current $10 \mathrm{nA}$, and a $5-10 \mu \mathrm{m}$ spot. The data wute processed using $\phi-\mathrm{p}-Z$ matrix correction procedures Data from Guidotti et al $(1994)$, $+\mathrm{O}$. Composition recalculated on the basis of $\mathrm{O}, \mathrm{H}, \mathrm{F}$ ard $\mathrm{Cl}$ equal to 6,12 , or 24 apfor 

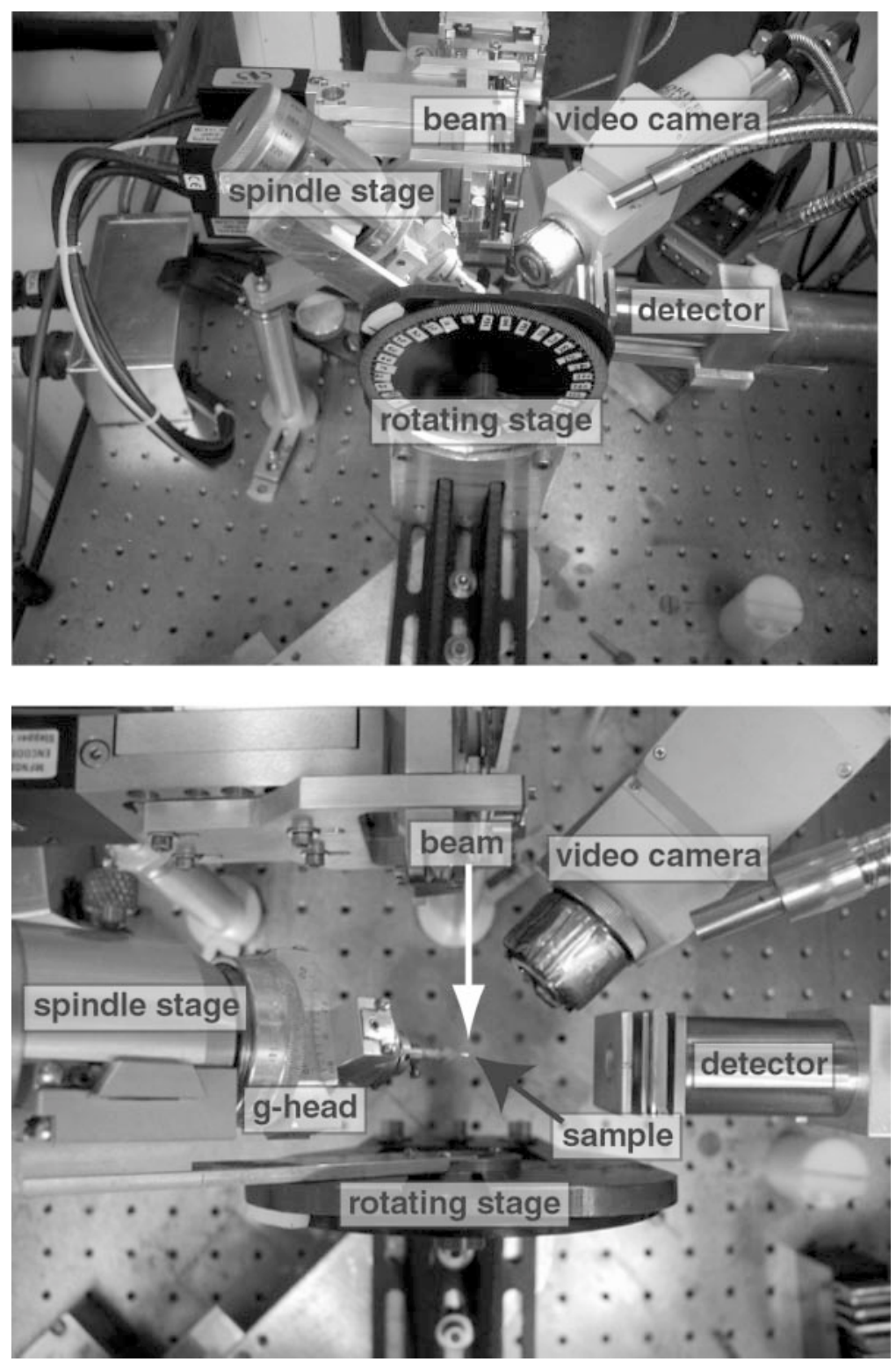

FIG. 2. Experimental set-up at beamline X26a, National Synchrotron Light Source, Brookhaven National Laboratory. (A) Photograph looking along the direction of the incident beam, showing spindle stage with a fixed goniometer head mounted on a rotating vertical stage. Camera for focusing is at upper right, and detector is at right, with the beam source in the background. (B) Bird's-eye view looking down on the same set-up as in A, showing the location of the sample. The path of the X-ray beam is given by the white arrow, and its polarization direction is parallel to the bread board. 
larger intervals to increase the efficiency of data collection. Each energy interval was counted between 5 and 20 live seconds (depending on the intensity of the mainedge signal) for a total acquisition time of about 20-30 minutes (including dead time) for each XANES spectrum. Counting times were adjusted to obtain at least $10^{4}$ counts per energy step at energies greater than the absorption edge. For additional details, see Delaney et al. (1996).

The measured intensities of the $\mathrm{Fe} K \alpha$ fluorescence line were normalized to the ion-chamber current and corrected for dead-time. Further normalization (e.g., to the edge step on the main edge) would be desirable but is impossible for this geometry because we are using single crystals of irregular shapes. The differential angle between the incident (and fluorescent) beam(s) and the surface of the grain changes the intensity of the entire spectrum, and we cannot quantitatively correct for this effect. Thus, we have chosen here to report our spectra with the standard procedure of normalizing to the raw counts in the ion chamber $\left(\mathrm{I}_{0}\right)$, which corrects only for variations in the beam flux.

A computer program was used to extract the preedge from the background and determine the centroid of the pre-edge. The program needs two points to be inserted; one point must be at the low side of the peak of interest, and the other at the high side of the peak. This chosen part of the spectrum is fitted to a secondorder polynomial (background) plus a Gaussian function (peak). The centroid of the peak is reproducible to within $1 \%$ if the peak of interest is the highest peak in the chosen part of the spectrum. A fit of a Lorentzian function did not give as good a result as that of the Gaussian function. Further details of the iterative fitting process and its effect on peak centroid positions are given in Bajt et al. (1994). At least five independent fits to each spectrum were made, and the results were averaged to result in the final position of the peak. Typical standard deviations on these fits were $<0.1 \mathrm{eV}$, so the baseline-subtraction approach and fitting method do not appear to greatly affect the fitted value of the peak centroid. Peak energies, given in absolute $\mathrm{eV}$, were determined by adding the energy of the magnetite pre-edge (7113.25 eV; cf. Petit et al. 2001, Wilke et al. 2001) to the relative $\mathrm{eV}$.

It would be mathematically possible to curve-fit the data presented here into individual peaks (four for octahedrally coordinated $\mathrm{Fe}^{2+}$ and two for tetrahedrally coordinated $\mathrm{Fe}$ ) after the methods of Wilke et al. (2001) and Petit et al. (2001). However, curve-fitting is not appropriate for the data collected here for three important reasons: 1) Our crystals have irregular shapes, such that the beam-to-sample geometry was variable at different orientations. Thus different amounts of self-absorption and excitation are evident in the spectra acquired at various orientations, and this will affect the peak intensities in a poorly understood fashion.
2) Samples for this study were purposely selected to have high Fe contents to assure sufficient signal-to-noise ratios in the resultant spectra. The disadvantage of this choice is that self-absorption effects due to the high $\mathrm{Fe}$ contents (that tend to damp out individual features) are apparent in all our spectra, particularly in the main-edge regions (where the edge step commonly used for normalization is located). Because the number of counts in the pre-edge is calculated relative to this edge step, preedge intensities can be affected by the high Fe contents. In short, both these factors render any interpretations of site geometry based on pre-edge intensity impossible, so they are not attempted here. The optimal way to make these measurements would be to use low-Fe compositions and oriented crystals ground to spheres. 3) Our measurements were made with a $\mathrm{Si}(111)$ monochromator (with roughly $1.5 \mathrm{eV}$ resolution) to ensure high beam-flux on our small samples. On the basis of the work presented here, it is now apparent that there will be sufficient signal to allow use of a higher-resolution monochromator.

In order to obtain $\mathrm{Fe}^{3+} / \Sigma \mathrm{Fe}$ values, it was necessary to run a set of standards, so the fayalite, magnetite, and hematite standards used by Bajt et al. (1994) (and routinely used at beamline X26a) were chosen for this purpose. A crystal of $100 \% \mathrm{Fe}^{3+}$ aegirine from the type locality (a different crystal of the oriented sample used in this study) was added to this suite because its Fe probably more closely resembles the $\mathrm{Fe}^{3+}$ in the pyroxenes, amphiboles, and micas. The unusual geometry of the beam employed in this experiment prevented use of the conventional standard mount (which is a $2.5-\mathrm{cm}$ round polished mount), so we created a special mount (Fig. 3). It consists of the four randomly oriented standards, each mounted on the thinned edge of a glass slide, arranged in a parallel geometry. This arrangement made it possible to place the standards in a plane perpendicular to the beam, which made it easier to locate the standards for analysis.

Once the peak positions of the standards were determined, then calibration lines relating peak-centroid energies to $\mathrm{Fe}^{3+} / \Sigma \mathrm{Fe}$ values were calculated in two ways. First, a calibration line based upon a regression of all the centroid energies for fayalite, magnetite, hematite, and aegirine versus their known $\mathrm{Fe}^{3+} / \Sigma \mathrm{Fe}$ was calculated. Given the dissimilarity between the hematite structure and the structures of the minerals studied herein, a second calibration line was determined using only fayalite, magnetite, and aegirine. These equations took the following form:

$$
\begin{aligned}
& \% \mathrm{Fe}^{3+}=54.53 \times \text { Position }_{\text {unknown }}+57.54 \\
& \text { with } \mathrm{r}^{2}=0.85 \text { for all four reference minerals, and } \\
& \% \mathrm{Fe}^{3+}=71.79 \times \text { Position }_{\text {unknown }}+62.75 \\
& \text { with } \mathrm{r}^{2}=0.92 \text { for the three reference minerals. }
\end{aligned}
$$




\section{Results: XANES Main-Edge SPeCtRA}

XANES spectra of each of the 12 samples, acquired at the three different optical orientations (X, Y, and Z), are shown in Figures 4 and 5 grouped according to mineral group; extracted pre-edge spectra are shown in Figures 6 and 7. The most straightforward conclusion to be drawn from these data is that the intensity of both preedge and main-edge peaks is variable as a function of orientation.

TAELE 3. XANES PEAK POSITIONS LV THE PYROKENE, AMPIUEOLE AND MICA SAMPLES

\begin{tabular}{|c|c|c|c|c|c|c|c|}
\hline & & Penk I & Penk 2 & Peak 3 & Peak 4 & Peak 5 & Pent 6 \\
\hline \multicolumn{8}{|c|}{ Pyraxene } \\
\hline En & $\mathrm{X}$ & & 7121.6 & 7125.1 & 7129.4 & & \\
\hline \multirow[t]{2}{*}{ Serra de Magé } & $\mathbf{Y}$ & & 7121.5 & 1124.6 & t]30.t & & \\
\hline & $Z$ & & 7121.2 & T] 25.3 & 7130.5 & & \\
\hline Aug & $x$ & & 7122.7 & & 71324 & & \\
\hline \multirow[t]{2}{*}{ Dish Hill DH-209 } & $\mathbf{Y}$ & 71179 & & 7125.9 & 7132.7 & & \\
\hline & $Z$ & & & 7126.2 & 7130.9 & & \\
\hline Ac & $\mathrm{X}$ & & & 7125.8 & 7131.9 & $71,38.7$ & \\
\hline \multirow[t]{2}{*}{ Acgit } & $\mathbf{Y}$ & 71186 & & $7] 25.8$ & 731.9 & 7138.7 & \\
\hline & $Z$ & & & 7125.65 & 7131.9 & 7138.7 & \\
\hline \multicolumn{8}{|c|}{ Amphtbole } \\
\hline $\mathrm{Krs}$ & $\boldsymbol{K}$ & & 7121.8 & 7124.6 & 71319 & & \\
\hline \multirow[t]{2}{*}{$\mathrm{AK}-\mathrm{MC}$} & $\mathrm{Y}$ & & 7121.3 & 7124.7 & 7130.1 & & \\
\hline & $\mathbf{Z}$ & & 7121.1 & 7125.4 & 7125,7 & & \\
\hline Krs & $\mathrm{X}$ & & & 7128.6 & 7133.7 & & \\
\hline \multirow[t]{2}{*}{$F R-12$} & $\mathrm{Y}$ & & 71232 & 71286 & 71325 & & \\
\hline & $z$ & & 7123.4 & 7128.2 & 7132.5 & & \\
\hline Ks: & $\mathrm{x}$ & & & $7] 27.5$ & 7133.1 & & \\
\hline \multirow[t]{3}{*}{ Тл } & $\mathbf{Y}$ & & & 7125.9 & 7131.0 & & \\
\hline & $\mathrm{Z}$ & & & $7] 25.1$ & 71315 & & \\
\hline & & & Micas & & & & \\
\hline $\mathrm{Ph}$ & $\mathrm{X}$ & & 7121.0 & 71251 & 71294 & & \\
\hline Dogossos O-H-49 & $\mathbf{Y}$ & & 7121.1 & 7125.4 & 7129,3 & & \\
\hline biotite & $\mathbf{Z}$ & & 7121.5 & 7125.6 & 7129.4 & & \\
\hline $\mathrm{Ann}$ & $x$ & & J]21.2 & 71250 & 7129.8 & & \\
\hline \multirow[t]{2}{*}{ Pikes Peak } & $\mathbf{Y}$ & & 7120.9 & 71250 & $7 ! 29.4$ & & \\
\hline & $Z$ & & T12I.0 & 7125.5 & 7129.8 & & \\
\hline \multirow{3}{*}{ Syothetic } & $x$ & & $T 121.3$ & 7125.7 & 7129.5 & & \\
\hline & $\mathbf{Y}$ & & & 7124.9 & 7129.6 & & \\
\hline & $Z$ & & 7120.9 & $\$ 1249$ & 7129.7 & & \\
\hline Ill & $\mathrm{x}$ & & $7] 21.2$ & 71264 & $7] 29.3$ & $7] 31.9$ & \\
\hline \multirow[t]{2}{*}{ Norkay ATL-34 } & $Y$ & & & 7125.5 & 7128.5 & 7131.6 & 7133.7 \\
\hline & $Z$ & & & 7123.5 & 7128.1 & 71333 & \\
\hline Ill & $x$ & & $7 / 211$ & $7+23.7$ & 7129.3 & 7179.5 & \\
\hline \multirow[t]{2}{*}{ Vorway ATL-35 } & $Y$ & & 7121.6 & 71244 & 7128.9 & 71315 & 7133.7 \\
\hline & $Z$ & & & 7124.4 & & 71315 & \\
\hline Ms. & $\mathrm{X}$ & & 71210 & 7125.1 & $7] 30.3$ & & \\
\hline Sebage SBG-83 & $\mathrm{Y}$ & & & 7125.1 & 7129.9 & & 7133.3 \\
\hline muscovite & $Z$ & & & 7124.5 & 71299 & & $7] 33.5$ \\
\hline
\end{tabular}

Nearly all the main-edge spectra collected in this study include peaks at energies of roughly 7121,7125 , and $7130 \mathrm{eV}$ (Table 3). Variations in the intensity of these three main peaks give rise to the dramatically different profiles observed for the different mineral groups. However, the similarity in their energies is not surprising, given the similarities in next-nearest neighbors in all these samples, which share $\mathrm{Fe}$ - and Mg-bearing parageneses. Additional peaks are present in spectra from individual mineral groups, as discussed below.

\section{Pyroxenes}

The pyroxene samples studied here represent two extremes of $\mathrm{Fe}^{3+}$ content $\left(100 \% \mathrm{Fe}^{2+}\right.$ Serra de Magé enstatite and $100 \% \mathrm{Fe}^{3+}$ aegirine), as well as an intermediate composition (augite from Dish Hill, California). The optical orientations for these minerals vary with composition, so it is necessary to consider these differences in order to compare the structural directions in each spectrum to those in other spectra of samples with different compositions.

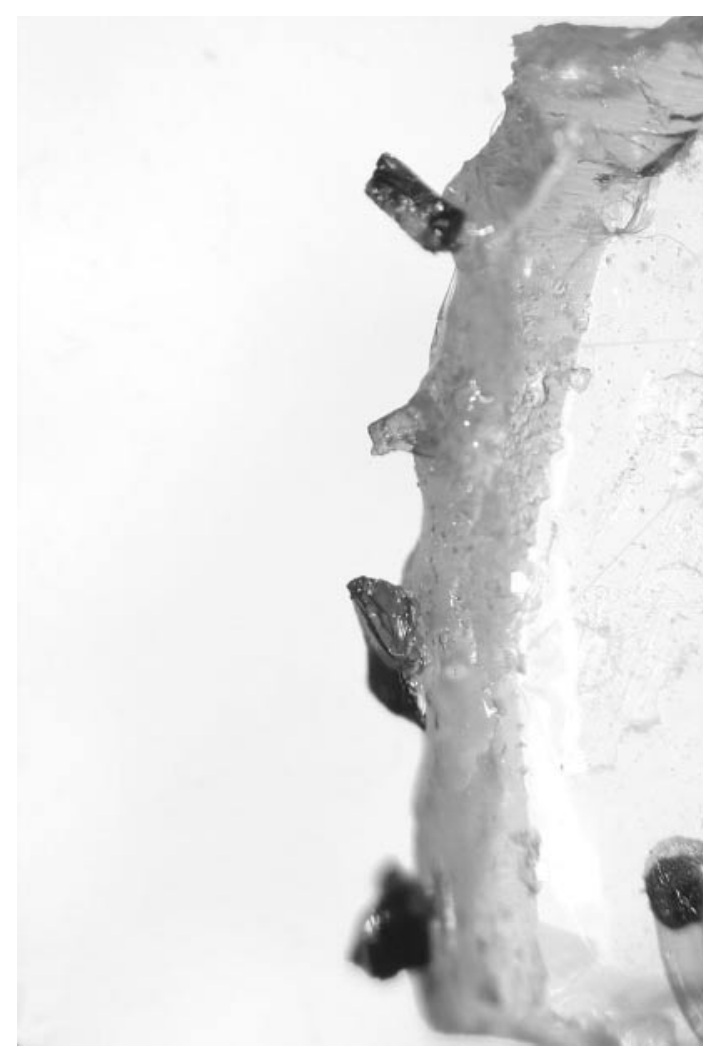

FIG. 3. Photomicrograph of the standard mount used in this experiment, showing (top to bottom) aegirine, hematite, fayalite, and magnetite. 
The three different orientations of Serra de Magé enstatite are among the most anisotropic of any of the samples measured in this study. The $\mathrm{Y}$ direction in enstatite is most similar to the $\mathrm{X}$ spectra for kaersutite
(Fig. 4), with two prominent peaks of similar intensity at 7121 and $7125 \mathrm{eV}$. The $\mathrm{Z}$ direction in enstatite resembles the $Z$ direction in kaersutite, though more defined structures are visible in the enstatite spectra (Fig. 4).
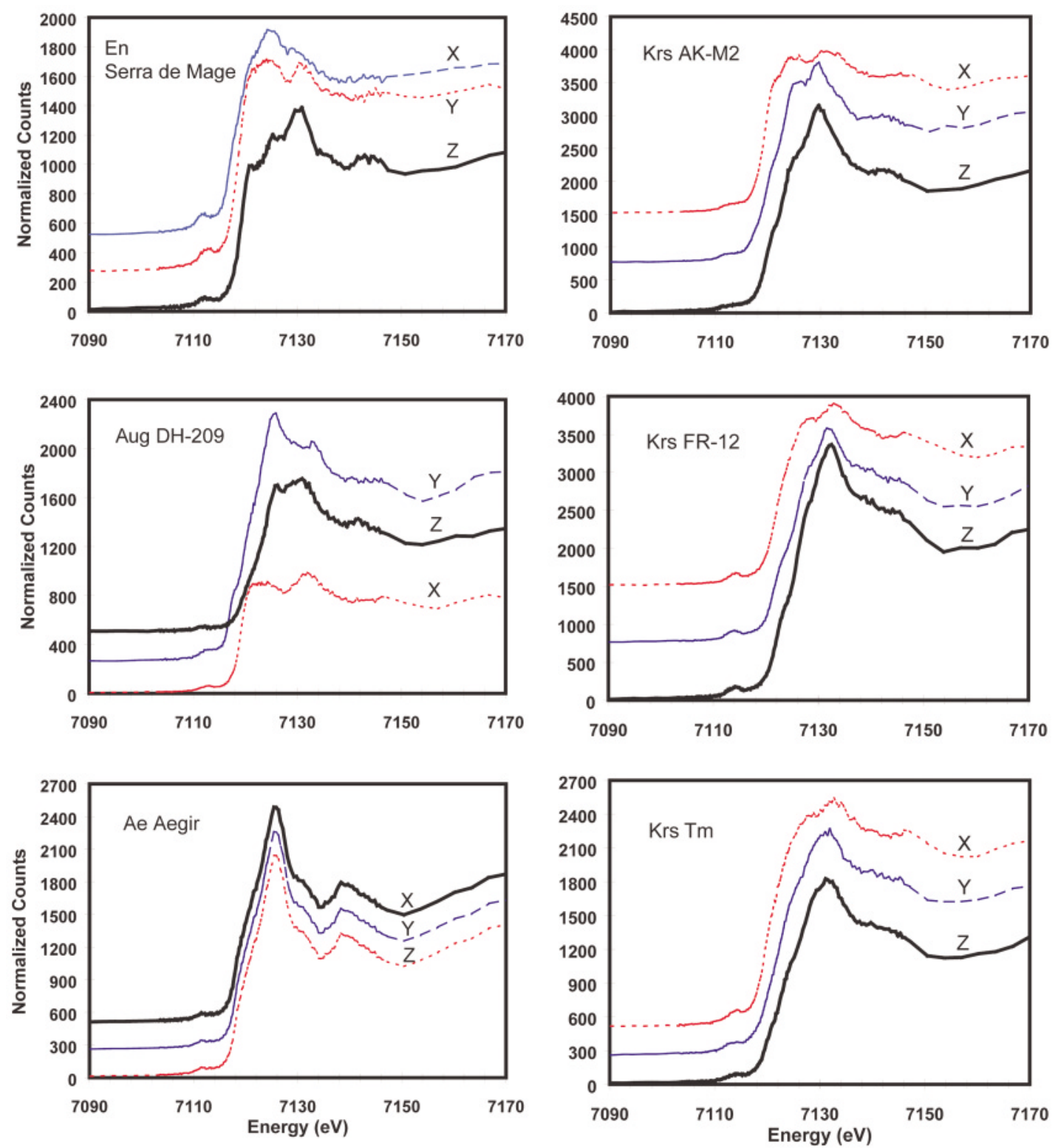

FIG. 4. XANES spectra of pyroxenes and amphiboles used in this study: Serra de Magé enstatite, Dish Hill 209 augite, aegirine from Aegir, Norway, and kaersutite samples AK-M2, FR-12, and Tm. Different orientations are offset in these plots because their spectra all have roughly the same intensity. Solid lines are spectra acquired with the beam parallel or nearly parallel to the length of the chains, large dashes are spectra polarized parallel or nearly parallel to the direction across the chains (on the layer of octahedra), and small dashes indicate spectra acquired parallel or nearly parallel to the stacking direction of each mineral. 
In the DH-209 augite, the optical orientations are at a large angle to the stacking or chain directions, so its $\mathrm{Z}$ spectrum cannot be compared to any of the others. Its $X$ spectrum is similar to the $\mathrm{X}$ spectrum in each of the kaersutite samples, and the $\mathrm{Y}$ spectrum of augite is somewhat similar to the $\mathrm{Y}$ spectrum of the kaersutite samples FR and Tm (Fig. 4). This sample also has a shoulder at $7117.9 \mathrm{eV}$ that is visible only in the $\mathrm{Y}$ orientation.

The same shoulder is also apparent in the Y spectrum of the aegirine sample, at an energy of $7118.6 \mathrm{eV}$. Its occurrence in both clinopyroxene samples, which both contain $\mathrm{Fe}^{3+}$, might support its assignment to $\mathrm{Fe}^{3+}$. The overall profiles (i.e., the relative intensities of the peaks) of all the optical orientations of the aegirine appear to be dissimilar to all the other spectra collected here. The three directions are also nearly identical. Similar populations of neighbors in all directions are thus giving rise to similar multiple scattering interactions.

\section{Amphiboles}

The main-edge features of the three samples of kaersutite studied here are similar, as would be expected from their similar compositions; unlike the case for pyroxenes, the optical orientations of these amphiboles all have the same relationships to the crystallographic di-

TABLE 4. PRE-EDGE CENTROIDS ARD INFERRED Fe' CONTENTS*

\begin{tabular}{|c|c|c|c|c|c|c|c|c|c|c|}
\hline & \multirow[t]{3}{*}{$x$} & \multirow[t]{3}{*}{$Y$} & \multirow[t]{3}{*}{$\boldsymbol{Z}$} & \multicolumn{2}{|c|}{$\mathrm{Fe}^{3-} \mathrm{Fe}^{3+}$} & \multicolumn{2}{|c|}{$\mathrm{Fe}^{\mathrm{s}+} \mathrm{Fe}^{\mathrm{d}}$} & \multicolumn{3}{|c|}{$\mathrm{Fe}^{\mathrm{j}-} \mathrm{Fe}^{\mathrm{y}} \mathrm{Fe} \mathrm{e}^{\mathrm{y}-}$} \\
\hline & & & & MS & $X$ & $Y$ & 7 & $\mathrm{x}$ & $\mathrm{Y}$ & $\boldsymbol{Z}$ \\
\hline & & & & \multicolumn{4}{|c|}{ Heth - Ae } & \multicolumn{3}{|c|}{ Atonly } \\
\hline \multicolumn{11}{|c|}{ Pyroutente } \\
\hline En Setra de Magé & -1.516 & -0.923 & -1.233 & & $-1]$ & 21 & 4 & -23 & 17 & -4 \\
\hline Alue Digh Hill DH. 209 & -0.885 & .0 .998 & $\cdot 1.512$ & 19 & 23 & $E T-$ & -11 & 19 & 12 & -23 \\
\hline Ae Alegir & 0.052 & 5.109 & 0.117 & $10 \%$ & 73 & 76 & 76 & 82 & 86 & 86 \\
\hline \multicolumn{11}{|c|}{ Amphibole } \\
\hline Kes AK-ML2 & $-0.70 !$ & -1.214 & 0.583 & 25 & 33 & 5 & 39 & 32 & -3 & 35 \\
\hline $\mathrm{Krs} F R-12$ & 0.708 & 0.410 & 0.705 & 100 & 107 & 921 & 107 & 126 & 900 & 126 \\
\hline Krs Tm & 0.247 & -0.360 & 0237 & $T T$ & 8.9 & $5]$ & B2 & 95 & 54 & 95 \\
\hline \multicolumn{11}{|c|}{ Mícas } \\
\hline Phi Opursoc O-H-49' & -1082 & -0.975 & -1.202 & 23 & 12 & 18 & 6 & 6 & 13 & -2 \\
\hline Ann Pikes Peak & -0.834 & -0861 & -0454 & 11 & 25 & 24 & 46 & 23 & 21 & 45 \\
\hline PA1] synthetic & 0.229 & -0134 & -0.158 & 62 & 82 & 63 & 61 & 94 & $\mathrm{TO}$ & 68 \\
\hline 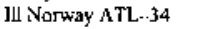 & -0.143 & 0.056 & 0.453 & 75 & 62 & 73 & 34 & 69 & & 109 \\
\hline 1]] Norway ATL-35 & -0.376 & 0.097 & 0. 146 & 55 & 50 & 75 & 78 & 53 & 85 & 88 \\
\hline WHE Selago SBG 83 & 0.770 & -0.677 & -0.117 & 32 & 29 & 34 & 64 & 27 & 33 & 71 \\
\hline
\end{tabular}

$\mathrm{Fe}^{3+}$ MS $=\mathrm{Fe}^{\mathrm{T}}$ as determined by Mossbauce spectroscopy lor bulk sample of the specimen, except in the case of the Serra de kfage enstatite, in which the iron is assumed to be all ferrous because the pyroxene coexists with Fe metal.

$\mathrm{Hem}+\mathrm{AE} \mathrm{Fe}$ " rcsults are determined using a calibracion line with both hesnatite and aegirine as the $100 \%$ Fed end-metribers.

Ae ondy $\mathrm{Fe}^{3+}$ results are determined using a cajbuation linte with orily aegirije as the $100 \% \mathrm{~F}^{3}$ " end-mermber.

- Fe contents are expessed as of total Fe. rections (Fig. 4). There are three significant features in the lower-energy portion of the main edge: a shoulder at roughly $7121 \mathrm{eV}$, and two prominent peaks at $\sim 7126$ and $\sim 7132 \mathrm{eV}$.

\section{Micas}

All the mica spectra consist of roughly the same three peaks seen in the pyroxenes and amphiboles, with energies at 7121, 7124-1725, and $7129 \mathrm{eV}$; the latter peak is systematically lower in energy than in pyroxenes and amphiboles (Fig. 5). The largest difference in X, Y, and $\mathrm{Z}$ directions within a single mineral group occurs in the micas, for which the $\mathrm{X}$ direction is distinctive. Particularly in dioctahedral micas (and even in the pre-edge spectra), the spectra acquired in the $X$ direction are far more intense than the $\mathrm{Y}$ and $\mathrm{Z}$ directions. Perhaps there is an increase in constructive interference of scattering events in this direction.

\section{Results: $\mathrm{Fe}^{3+} / \Sigma \mathrm{Fe}$ Results BASED on Pre-Edge Spectra}

It is apparent from inspection of Figures 6 and 7 that the centroids of pre-edge features in all the samples vary as a function of orientation. The orientation effect is the least pronounced in the spectra of trioctahedral micas, and the most obvious in the spectra of dioctahedral micas. Peak-centroid positions and $\mathrm{Fe}^{3+} / \Sigma \mathrm{Fe}$ values for all twelve samples at the three optical orientations are given in Table 4.

\section{DisCUSSION}

A proper interpretation of the 36 spectra collected for this study requires consideration of the inter-relationships among the optical orientations of the various mineral groups (Table 5, Fig. 8). Thus, the following discussion is organized according to optical orientations to facilitate comparisons among these different structures.

\section{TABLE 5. SUMMARY OF STRLCTURAL AKD} OPTICAL RTTER-RELAT]ONSHIPS

\begin{tabular}{|c|c|c|}
\hline $\begin{array}{c}\text { Crystatlographic Axes } \\
\text { Relaled on Stmictural } \\
\text { Elements }\end{array}$ & Optical Directions & Exceptions \\
\hline$b / /$ al] the actahedrat laycrs & $\begin{array}{l}\text { It. the octahedral luyer, } \\
b=\mathrm{Y}\end{array}$ & $\begin{array}{l}b=X \text { in } C p x \text { and } \\
b=Z \text { in djoctahedsal mick }\end{array}$ \\
\hline 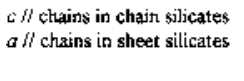 & $\begin{array}{l}Z \text { is } / / \text { ot }-/ / \text { lo the } \\
\text { chaing }\end{array}$ & $\begin{array}{l}\text { Ae }(\mathrm{X}-/ / \text { chains }) \text { and } \\
\text { dioctahedral mica } \\
(\mathrm{Y} \text { - / chains })\end{array}$ \\
\hline 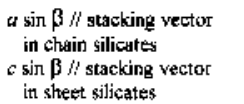 & $\begin{array}{l}\mathrm{X} \text { is } / / \text { or } \sim / / \text { tir } \\
\text { the stacking directions }\end{array}$ & $\begin{array}{l}\text { Ae }(Z-/ / \text { stacking } \\
\text { disectiont and } E n \\
(\mathrm{C}-/ / / \text { stacking diretion) }\end{array}$ \\
\hline
\end{tabular}




\section{$X$ orientation in sheet silicates}

The $\mathrm{X}$ direction in the sheet silicates is nearly parallel to the $c$ crystallographic axis, which in turn is nearly perpendicular to the perfect (001) cleavage (Fig. 8). As for their optical properties, the direction perpendicular to the cleavage plane $(\mathrm{X})$ is very different from the directions within the $a-b$ plane ( $\mathrm{Y}$ and $\mathrm{Z}$ ). This is exactly what is observed (Fig. 5), especially for the trioctahedral micas.
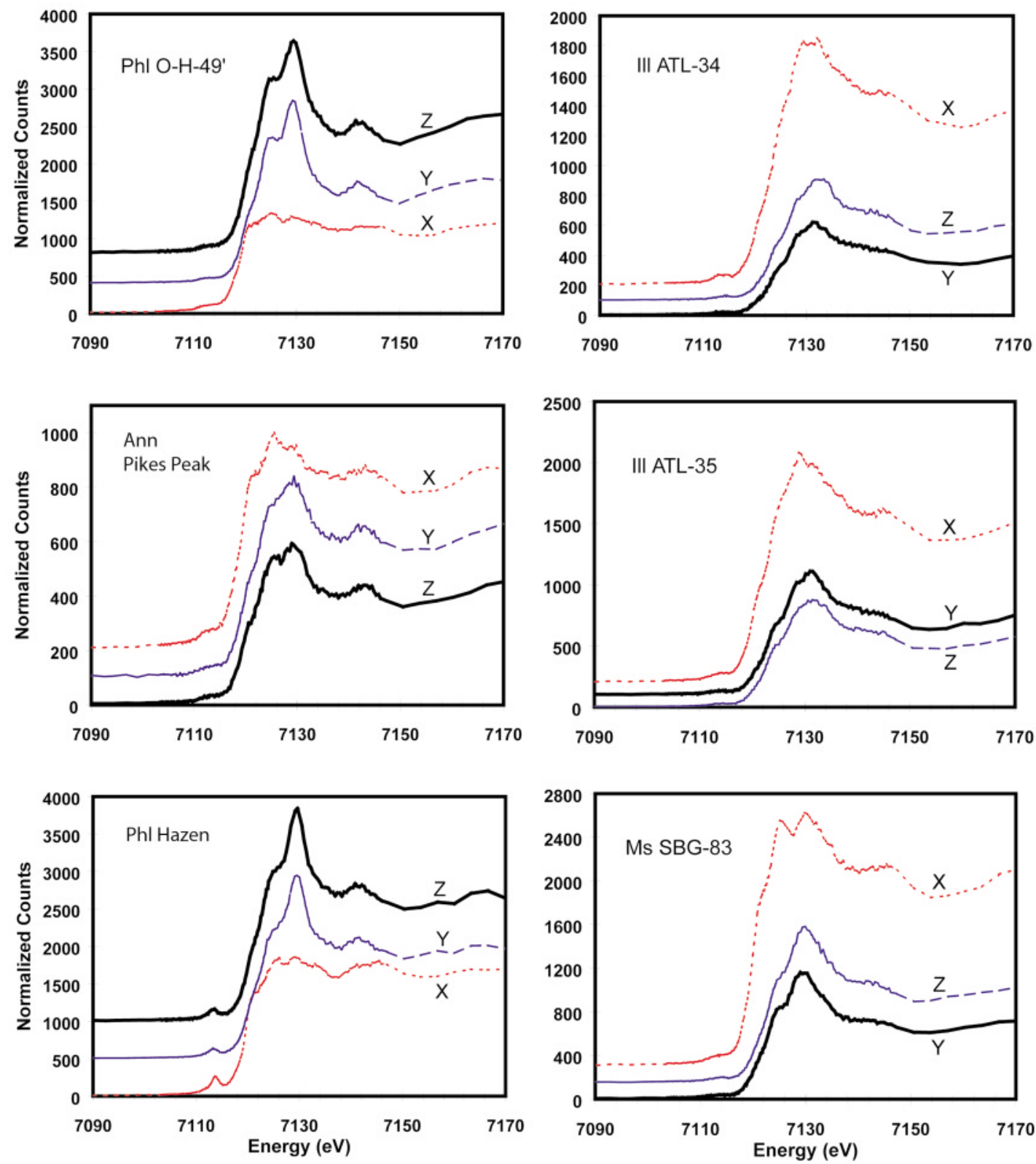

FIG. 5. XANES spectra of trioctahedral micas from western Maine (phlogopite O-H-49'), Pikes Peak, Colorado (annite), and a synthetic phlogopite from R. Hazen, along with dioctahedral micas ATL-34, ATL-35 (both from Norway), and SBG-83 (western Maine). Solid lines are spectra acquired with the beam parallel or nearly parallel to the length of the chains, large dashes are spectra polarized parallel or nearly parallel to the direction across the chains (on the layer of octahedra), and small dashes indicate spectra acquired parallel or nearly parallel to the stacking direction of each mineral. 

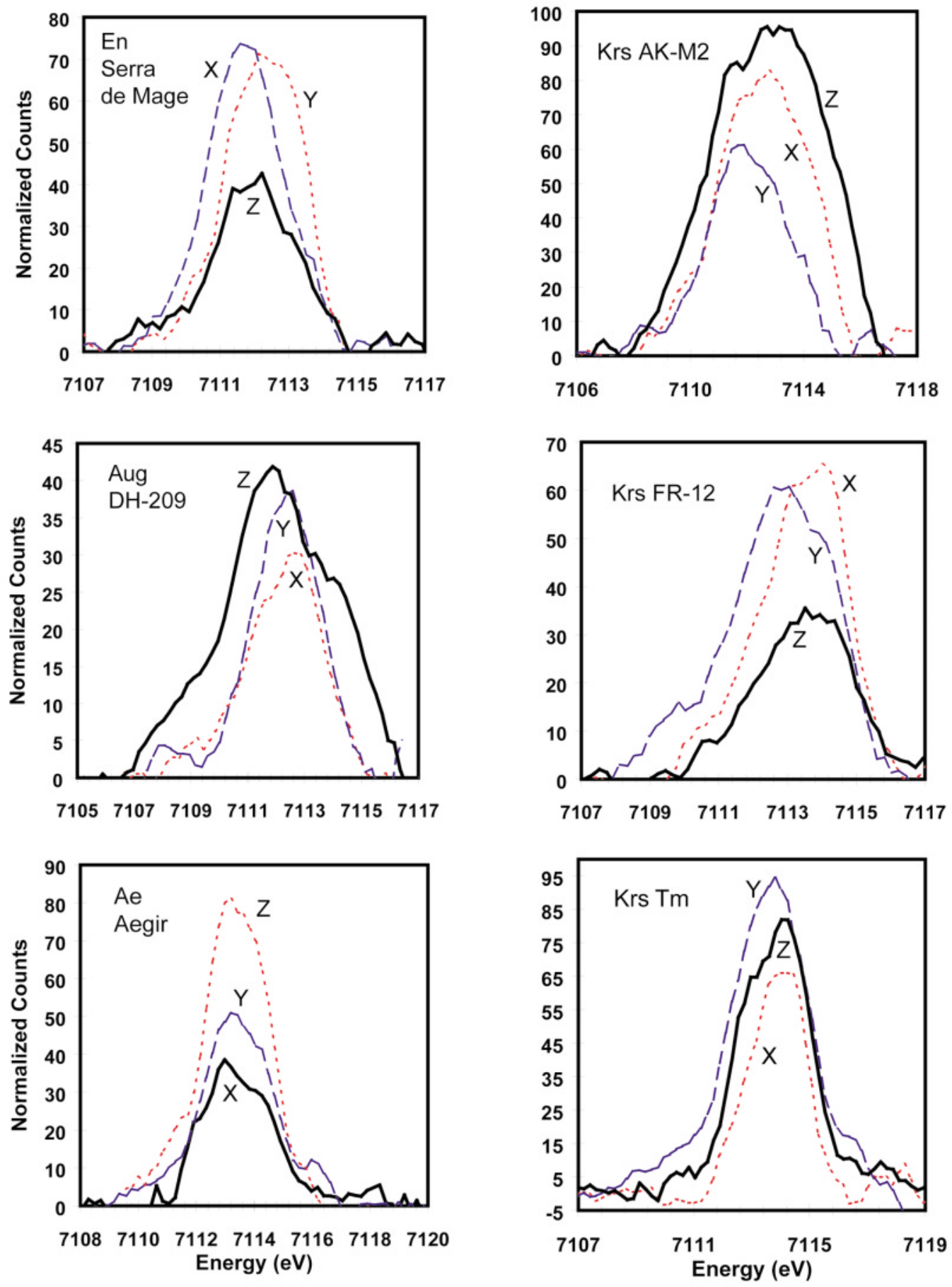

FIG. 6. Extracted pre-edge spectra of pyroxenes and amphiboles: Serra de Magé enstatite, Dish Hill 209 augite, aegirine from Aegir, and kaersutite samples AK-M2, FR-12, and Tm. Solid lines are spectra acquired with the beam parallel or nearly parallel to the length of the chains, large dashes are spectra polarized parallel or nearly parallel to the direction across the chains (on the layer of octahedra), and small dashes indicate spectra acquired parallel or nearly parallel to the stacking direction of each mineral. 

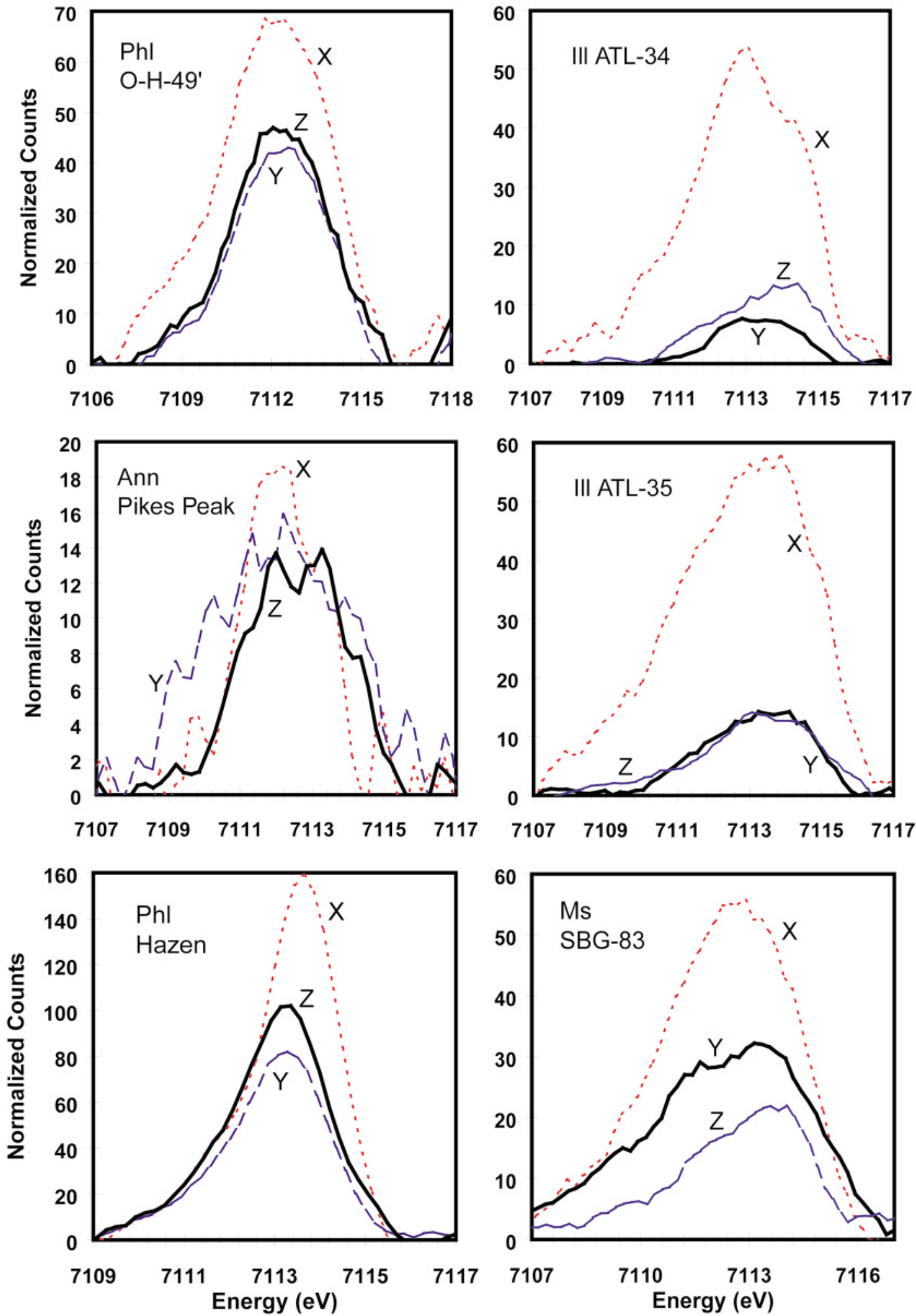


\section{$Y$ and $Z$ orientations in micas}

The $\mathrm{Y}$ and the $\mathrm{Z}$ orientations for micas are very similar because the structure is very similar throughout the $a-b$ plane (Fig. 8). Thus, all the $\mathrm{Y}$ and $\mathrm{Z}$ spectra of micas should look basically the same for each of the six compositions (Fig. 5). Where compositional differences exist, $b$ corresponds to $\mathrm{Z}$ for dioctahedral micas and to $\mathrm{Y}$ in trioctahedral micas, so that the $\mathrm{Z}$ of dioctahedral micas must be compared to the $\mathrm{Y}$ of trioctahedral micas and vice versa. This well-known switch of $\mathrm{Z}$ and $\mathrm{Y}$ optical directions possibly occurs because the orientation of the $\mathrm{OH}$ vector in a trioctahedral mica is perpendicular to the $a-b$ plane, whereas the $\mathrm{OH}$ vector in a dioctahedral mica rotates toward the $a-b$ plane, preferentially along the $b$ crystallographic axis, creating greater polarization of the $\mathrm{OH}$ vector in that direction, thus slowing the light and causing an increase in index of refraction (and the optical orientation). This phenomenon would also be expected to occur with X-rays.

\section{Mica spectra related to amphibole spectra}

The $\mathrm{Z}$ direction in dioctahedral micas is consistently similar to the $\mathrm{Y}$ direction in trioctahedral micas and kaersutite (Figs. 4, 5). $Z_{\mathrm{Krs}}$ is roughly equal to $Z_{\text {trioct }}$, which is also similar to $\mathrm{Y}_{\text {dioct }}(c f$. Fig. 8), because all these orientations lie along the chain directions (i.e., along the 5.2 A repeat direction). A sheet in a sheet silicate is nothing more than a set of polymerized silicate chains joined to each other. From this perspective, these two crystallographic directions can be considered the same. Unfortunately, for the understanding of systematic relationships, the $a$ and the $c$ crystallographic axes are switched between the chain and sheet silicates. This switch is apparent from the identical 5.2 A repeat along the chains of polymerized tetrahedra in both mineral groups.

\section{$Y$ and $X$ orientations within amphibole-group minerals}

For the three samples of kaersutite examined in this study (and most other clinoamphiboles), the $b$ crystallographic axis corresponds to the $\mathrm{Y}$ vibration direction,

FIG. 7. Extracted pre-edge spectra of trioctahedral micas from western Maine (phlogopite O-H-49'), Pikes Peak, Colorado (annite), and the synthetic phlogopite, along with dioctahedral micas ATL-34, ATL-35 (both from Norway), and SBG-83 (western Maine). Solid lines are spectra acquired with the beam parallel or nearly parallel to the length of the chains, large dashes are spectra polarized parallel or nearly parallel to the direction across the chains (on the layer of octahedra), and small dashes indicate spectra acquired parallel or nearly parallel to the stacking direction of each mineral. which in turn is oriented along the strips of octahedra (Fig. 8B). This is analogous to the $b=\mathrm{Y}$ orientation in the trioctahedral sheet silicates. The $\mathrm{X}$ direction in kaersutite corresponds approximately to the $a$ crystallographic axis, which in turn relates to the stacking vector for the well-known double I-beams in the structure (Fig. 8B). This direction relates to the "T-O-T" stacking in the sheet silicates, and the $c$ axis.

As with the trioctahedral micas, the kaersutite spectra acquired in the $\mathrm{X}$ direction are different from those in the $\mathrm{Y}$ and $\mathrm{Z}$ directions (Fig. 4). Unlike the micas, the spectra in the $\mathrm{Y}$ and $\mathrm{Z}$ directions are not identical (though they are similar), because the structure parallel to the "I-beams" differs from the structure across them.

\section{$X$ and $Z$ orientations for pyroxenes}

The $\mathrm{Z}$ direction in the Serra de Magé enstatite corresponds to the $c$ direction, whereas in aegirine, the $\mathrm{X}$ direction is within $6^{\circ}$ of $c$. Therefore, there should be a similarity between $\mathrm{X}_{\mathrm{Ae}}$ and $\mathrm{Z}_{\mathrm{En}}$, but this is not exactly observed (Fig. 4); although the peak positions are similar, the intensities are different. In the Dish Hill augite, there is a $42^{\circ}$ angle between $c$ and $\mathrm{Z}$; its $\mathrm{Z}$ spectrum thus should be a composite of the $\mathrm{X}_{\mathrm{Ae}}$ and $\mathrm{Z}_{\mathrm{Ae}}$, and the $Z_{E n}$ and $Y_{E n}$. Accordingly, comparisons of $Z_{\text {Aug }}$ to any other orientations cannot be made directly.

\section{$Y$ orientation for chain silicates}

The Y direction in the enstatite corresponds to the stacking direction of the I-beams in the pyroxene structure, which in turn corresponds to the $\mathrm{X}$ direction in the kaersutite structure (Figs. 8B, C). Thus, $\mathrm{Y}_{\text {En }}$ should resemble $X_{\mathrm{Krs}}$, and it does (Fig. 4). For five out of six of the chain silicates studied here, Y corresponds to $b$. Thus, all those Y spectra should be similar (they are), with the $\mathrm{Y}$ for the kaersutite slightly different owing to its double-chain nature. The exception is the Serra de Magé enstatite, for which $b$ is equal to X. Therefore, its $\mathrm{X}$ spectrum should be similar to the $\mathrm{Y}$ spectra of the other five (and it is).

\section{Inter-relationships among spectra of pyroxenes, amphiboles, and micas}

We speculate that directions along the length of the chains ( $c$ for pyroxenes, $c$ for amphiboles, and $a$ for micas) should have similar XANES spectra, with corresponding changes in the optical directions. Thus, $\mathrm{Y}_{\text {dioct }}$ $\approx \mathrm{Z}_{\text {trioct }} \approx \mathrm{Z}_{\mathrm{Krs}} \approx \mathrm{Z}_{\mathrm{En}} \approx \mathrm{X}_{\mathrm{Ae}}$ (Dish Hill augite is intermediate) (Fig. 8). However, the similarities should be the strongest between spectra taken along the $c$ crystallographic axes in pyroxenes and those in amphiboles. In a similar manner, the spectra taken along the $b$ crystallographic axes (along the layer of octahedra, across the Ibeam; $c f$. Fig. 8B) should be similar for all groups $\left(\mathrm{Z}_{\text {dioct }}\right.$ $\approx \mathrm{Y}_{\text {trioct }} \approx \mathrm{Y}_{\mathrm{Krs}} \approx \mathrm{X}_{\mathrm{En}} \approx \mathrm{Y}_{\text {Aug }}$ ), and more similar for the 
A. pyroxenes

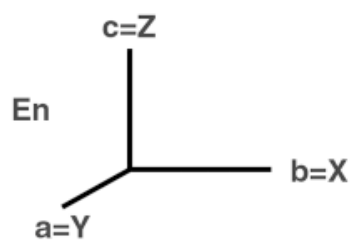

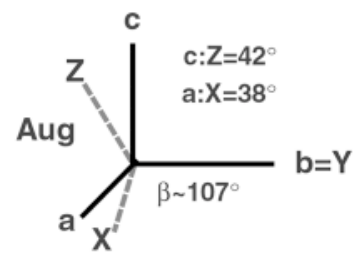

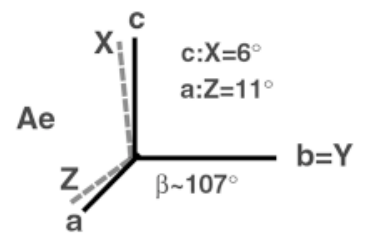

amphiboles

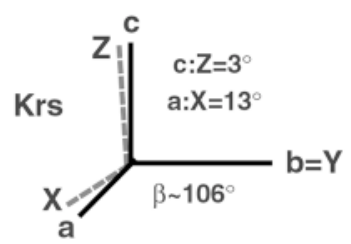

chains to sheets

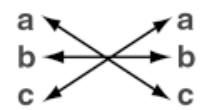

micas

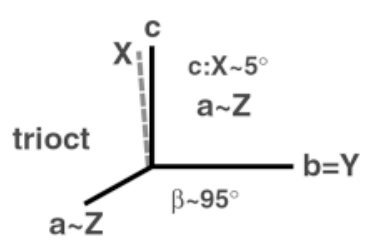

B.

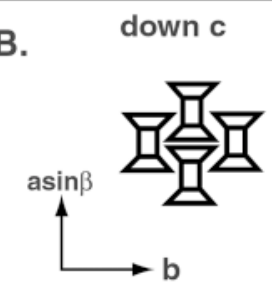

C.

En $\quad \mathrm{c}=\mathrm{Z}=\mathrm{X}$

Aug ${\stackrel{\mathrm{a}}{\mathrm{a} X=38^{\circ}} \mathrm{c} Z=42^{\circ}}_{\mathrm{b}=\mathrm{Y}}$

$\mathrm{Ae} \quad \stackrel{\mathrm{a}: \mathrm{Z}=11^{\circ} \mathrm{X}=6^{\circ}}{\mathrm{b}=\mathrm{Y}}$
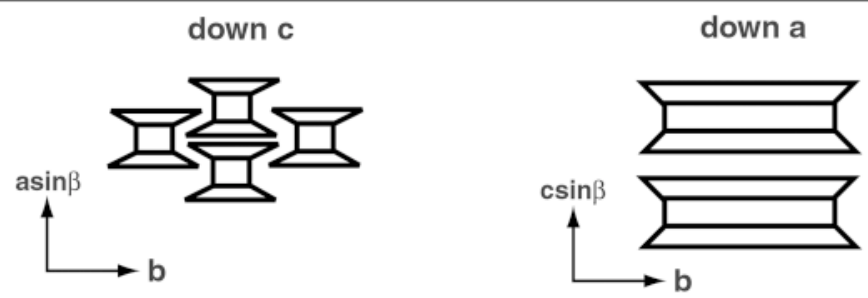

$b=Y$

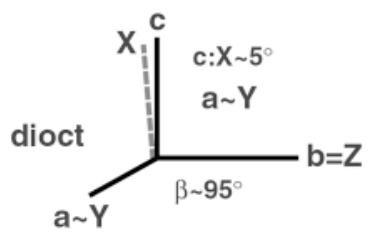


amphiboles and micas. Lastly, spectra acquired along the stacking direction, which is the $a$ crystallographic direction for pyroxene and amphiboles, and the $c$ crystallographic direction in sheet silicates, should also be similar.

\section{USE OF XANES PRE-EDGES to Determine $\mathrm{Fe}^{3+} / \Sigma \mathrm{Fe}$}

One of the original motivations for this work was to characterize the variation in pre-edge centroid position as a function of orientation because anisotropy in preedge position was believed to be the major source of error in $\mathrm{Fe}^{3+} / \Sigma \mathrm{Fe}$ determinations by XANES. To do a correct assessment of the errors associated with these measurements, we need to evaluate a minimum of four different phenomena: A) the formal statistics of X-ray generation, B) the effect of sample geometry as seen by the X-ray microbeam, C) crystallographic orientation, and D) secondary fluorescence from potential contaminants in the excitation volume (e.g., inclusions).

Past studies (beginning with that of Bajt et al. 1994) using the peak centroid approach have consistently quoted errors of $10-15 \%$ absolute on $\mathrm{Fe}^{3+} / \Sigma \mathrm{Fe}$ results based on comparison with Mössbauer and wet-chemical measurements on the same samples. These errors represent the sum of factors $\mathrm{A}, \mathrm{B}$, and $\mathrm{D}$ only, because sample geometry $(C)$ remains constant for grains studied on polished surfaces. In the current study, all four of these factors contribute to error, so the resultant errors on $\mathrm{Fe}^{3+} / \Sigma \mathrm{Fe}$ would be expected to be higher.

Table 4 gives the measured pre-edge centroids, along with the resultant $\mathrm{Fe}^{3+} / \Sigma \mathrm{Fe}$ percentages inferred from each spectrum. Values of $\mathrm{Fe}^{3+} / \Sigma \mathrm{Fe}$ in the table were calculated in two different ways: 1) using fayalite, magnetite, hematite, and aegirine as the standards for the calibration line, and 2) using only fayalite, magnetite, and aegirine. The two methods give results that are slightly different, but the end result is the same: there is a significant variation in the calculated $\mathrm{Fe}^{3+} / \Sigma \mathrm{Fe}$ values as a result of orientation. Note that the spectra of the standards were acquired from randomly oriented crys- tals, albeit with the same exact orientation used in each of the replicated spectra.

These data suggest that the error in $\mathrm{Fe}^{3+} / \Sigma \mathrm{Fe}$ is roughly $\pm 20 \%$ for pyroxenes and amphiboles and probably $\pm 10-15 \%$ for micas if peak centroid fits are used. These results were expected, given the previous work by Galoisy et al. (2001) and Wilke et al. (2001), and they strongly support the need to fit pre-edges to component peaks corresponding to individual transitions rather than to simplified centroids.

In future studies of thin sections, it may be possible to reduce the contributing factors to the errors to only those arising from X-ray statistics (A) and secondary fluorescence (D). On the basis of the dependence of the sheet silicate spectra on orientation, there is a large anisotropy between the XANES spectra between (parallel to) the sheets versus those perpendicular to the sheets. Thus, these biaxial minerals behave like uniaxial minerals because all vibrations in the (001) planes are very similar. Accordingly, the orientational dependence of the XANES spectra can be minimized for thin-section work on micas by rotating traces of the (001) cleavage parallel to the polarization direction of the synchrotron source. The standard would have to oriented in the same way as the unknowns. In the amphibole-group minerals, the spectra acquired parallel to the $c$ axis are most dissimilar to those acquired at the two mutually perpendicular directions to $c$. Thus, orientational effects would be minimized by rotating the long axis of the amphibole parallel to the beam, and by using similarly oriented standards. In the pyroxenes, the three spectra (X, Y, and Z) are all very different. Thus, determinations of the $\mathrm{Fe}^{3+}$ contents in pyroxene using preedge position will have to be done using oriented samples and standards if superior data are to be acquired.

Will it be worth it to employ precisely oriented unknowns and standards, along with careful peak fits to extracted pre-edges (guided by predictions from crystal-field theory), to obtain highly accurate $\mathrm{Fe}^{3+} / \Sigma \mathrm{Fe}$ values from the study of minerals in thin section? The answer is a resounding YES. The last 30 years of electron-microprobe study of mineral compositions in thin

FIG. 8. Schematic representation of the optical orientations and their relationships to the main structural units in the pyroxenes, amphiboles, and micas. A. Representative optical orientations of the minerals studied in this paper. The three pyroxenes all have different optical orientations, the three amphiboles have the same optical orientation (to within $1^{\circ}$ ), and the micas are divided into the trioctahedral and dioctahedral subgroups with similar optical orientations, except for the switching of $Y$ and Z. Note that the $a$ and $c$ crystallographic axes switch between the chains silicates and sheet silicates. Equal signs are used for cases where we actually determined the optical orientation, and approximation signs are used for cases where we took the values for the optical orientation from the literature. Solids lines represent crystallographic axes $(a, b, c)$, and dashed lines, the optical directions (X, Y, Z). B. Schematic representation of the "I-beam" structures of pyroxenes, amphiboles, and micas projected down the $c$ axis for chain silicates and $a$ axis for the sheet silicates. Note how the $b$ axis is invariably oriented across the strips of octahedra. C. Two-dimensional projections down $c$ for chain silicates and down $a$ for the sheet silicates. Again note that $b$ corresponds to the strip of octahedra in every case, and in four of the six sketches, $b$ equals $\mathrm{Y}$, whereas $b$ equals $\mathrm{X}$ for enstatite and $b$ equals $\mathrm{Z}$ for dioctahedral mica. 
sections have shown us that many critically important petrological and mineralogical processes are manifest only at microscales. At the present time, microXANES methods present the most promising technology for nondestructive study of minerals and glasses in situ in thin sections. The exciting prospect of achieving $\mathrm{Fe}^{3+} /$ $\Sigma \mathrm{Fe}$ results with errors of $<2-3 \%$ absolute is within reach, and it offers tremendous potential for the future study of tiny samples from extraterrestrial as well as terrestrial parageneses.

\section{ACKNOWLEDGEMENTS}

We thank Charles Guidotti, Robert Hazen, Spike Berry, Dan Lux, Anne McGuire, and Howard Wilshire for use of samples for this study, Martin Yates for the $U$ Maine EMPA, Nick Foit for the loan of goniometer heads, and Brendan Twamley for assistance with X-ray orientation of the samples. This paper was greatly improved by thoughtful reviews by A. Mottana, E. Paris, and R.F. Martin. This work was supported by NSF grants EAR-9806182, EAR-9909587, EAR-9909588, NAG5-8820, NAG5-9528, NAG5-10424, and DOEGeosciences DE-FG02-92ER14244.

\section{REFERENCES}

Andersen, T.B., Berry, H.N., IV, LuX, D.R, \& ANDresen, A. (1998): The tectonic significance of pre-Scandian ${ }^{40} \mathrm{Ar} /{ }^{39} \mathrm{Ar}$ phengite cooling ages in the Caledonides of western Norway. J. Geol. Soc. London 155, 297-309.

BAIR, R.A. \& GoDDARD, W.A., III (1980): Ab initio studies of the X-ray absorption edge in $\mathrm{Cu}$ complexes. I. Atomic $\mathrm{Cu}^{2+}$ and $\mathrm{Cu}(\mathrm{II}) \mathrm{Cl}_{2}$. Phys. Rev. B 22, 2767-2776.

Bajt, S., Sutton, S.R. \& Delaney, J.S. (1994): X-ray microprobe analysis of iron oxidation states in silicates and oxides using X-ray absorption near edge structure (XANES). Geochim. Cosmochim. Acta 58, 5209-5214.

Benfatto, M., Congui Castellano, G., Daniele, A. \& Della LONGA, S. (2001): MXAN: a new software procedure to perform geometrical fitting of experimental XANES spectra. J. Synchr. Rad. 8, 267-269.

BerzeLIUs, J. (1835): Aegirin (Esmark). Neues Jahrb Mineral., Geognosie, Geologie und Petrefaktenkunde (von Leonard und Bronn), 184-185.

BLoss, F.D. (1981): The Spindle Stage: Principles and Practice. Cambridge University Press, Cambridge, U.K.

Brigatti, M.F., Galli, E., Medici, L., Poppi, L., Cibin, G., Marcelli, A. \& Mottana, A. (2001): Chromiumcontaining muscovite; crystal chemistry and XANES spectroscopy. Eur. J. Mineral. 13, 377-389.

Brouder, C.J. (1990): Angular dependence of X-ray absorption spectra. J. Phys. 2, 701-738.
Brown, G.E., Jr., Calas, G., Waychunas, G.A. \& Petiau, J. (1988): X-ray absorption spectroscopy and its applications in mineralogy and geochemistry. In Spectroscopic Methods in Mineralogy and Geology (F.C. Hawthorne, ed.). Rev. Mineral. 18, 431-511.

Calas, G. \& Petiau, J. (1983): Coordination of iron in oxide glasses through high-resolution K-edge spectra: information from the pre-edge. Solid State Commun. 48, 625-629.

Delaney, J.S., BaJT, S., SutTon, S.R. \& DyaR, M.D. (1996): In situ microanalysis of $\mathrm{Fe}^{3+} / \Sigma \mathrm{Fe}$ ratios in amphibole by X-ray Absorption Near Edge Structure (XANES) spectroscopy. In Mineral Spectroscopy: A Tribute to Roger G. Burns (M.D. Dyar, C.A. McCammon \& M.W. Schaefer, eds.). The Geochemical Society, Spec. Publ. 5, 165-171.

Dyar, M.D., Sutton, S.R. \& BAJT, S. (1998): Redox ratios with relevant resolution: solving an old problem by using the Synchrotron microXANES probe. Geology 26, 139-142.

DrÄGER, G., FrAhM, R., MATERLIK, G. \& BRÜMMER, O. (1988): On the multiplet character of the X-ray transitions in the pre-edge structure of Fe K absorption spectra. Phys. Stat. Sol. 146, 287-294.

Dyar, M.D., Delaney, J.S. \& Sutton, S.R. (2001): Fe XANES spectra of iron-rich micas. Eur. J. Mineral. 13, 1079-1098.

Gunter, M.E., Delaney, J.S. Lanzarotti, A. \& SutTon, S.R. (2002): Use of the spindle stage for orientation of single crystals for microXAS: isotropy and anisotropy in Fe-XANES spectra. Am. Mineral. 87, 15001504.

Mackwell, S.J., McGuire, A.V., Cross, L.R. \& Robertson, J.D. (1993): Crystal chemistry of $\mathrm{Fe}^{3+}$ and $\mathrm{H}^{+}$ in mantle kaersutites: implications for mantle metasomatism. Am. Mineral. 78, 968-979.

Martin, S.V., Mackwell, S.J., Carpenter, S., Grant, C.A. \& McGuiRe, A.V. (1996): Crystal chemistry of $\mathrm{Fe}^{3+}, \mathrm{H}^{+}$, and $\mathrm{D} / \mathrm{H}$ in mantle-derived augite from Dish Hill: implications for alteration during transport. In Mineral Spectroscopy: A Tribute to Roger G. Burns (M.D. Dyar, C.A. McCammon \& M.W. Schaefer, eds.). The Geochemical Society, Spec. Publ. 5, 289-304.

Galoisy, L., Calas, G. \& Arrio, M.A. (2001): Highresolution XANES spectra of iron in minerals and glasses: structural information from the pre-edge region. Chem. Geol. 174, 307-319.

Giuli, G., Paris, E., Wu, Z., Brigatti, M.F., Cibin, G., Mottana, A. \& Marcelli, A. (2001): Experimental and theoretical XANES and EXAFS study of tetra-ferriphlogopite. Eur. J. Mineral. 13, 1099-1108.

Guidotti, C.V. \& Dyar, M.D. (1991): Ferric iron in metamorphic biotite and its petrologic and crystallochemical implications. Am. Mineral. 76, 161-175. 
YATES, M.G., DYAR, M.D. \& TAYLOR, M.E. (1994): Petrogenetic implications of $\mathrm{Fe}^{3+}$ content of muscovite in pelitic schists. Am. Mineral. 79, 793-795.

Gunter, M.E. \& Twamley, B. (2001): A new method to determine the optical orientation of biaxial minerals: a mathematical approach. Can. Mineral. 39, 1701-1711.

Hahn, J.E., Scott, R.A., Hodgson, K.O., Doniach, S., DesJardins, S.R. \& Solomon, E.I. (1982): Observation of an electric quadrupole transition in the X-ray absorption spectrum of a $\mathrm{Cu}(\mathrm{II})$ complex. Chem. Phys. Lett. 88, 595598.

Harlow, G.E., Nehru, C.E., Prinz, M., Taylor, G.J. \& Keil, K. (1979): Pyroxenes in Serra de Magé: cooling history in comparison with Moama and Moore County. Earth Planet. Sci. Lett. 43, 173-181.

Manceau, A., Chateigner, D. \& Gates, W.P. (1998): Polarized EXAFS, distance-valence least squares modeling (DVLS) and quantitative texture analysis aproaches to the structural refinements of the Garfield nontronite. Phys. Chem. Minerals 25, 347-365.

Mottana, A., Marcelli, A., Cibin, G. \& Dyar, M.D. (2002): $\mathrm{X}$-ray absorption spectroscopy of the micas. In Advances in Micas (A.S. Mottana \& F.P. Sassi, eds.). Rev. Mineral. Geochem. 46, 371-411.

Robert, J.-L., Marcelli, A., Giuli, G., Della Ventura, G., Paris, E. \& Wu, Ziyu (1997): Octahedral versus tetrahedral coordination of $\mathrm{Al}$ in synthetic micas determined by XANES. Am. Mineral. 82, 497-502.

Petit, P.-E., Farges, F., Wilke, M. \& Solé, V.A. (2001): Determination of the iron oxidation state in Earth materials using XANES pre-edge information. J. Synchr. Rad. 8 952-954.

Pettifer, R.F., Brouder, C., Benfatto, M., Natoli, C.R., Hermes, C. \& Ruiz López, M.F. (1990): Magic-angle theorem in powder X-ray-absorption spectroscopy. Phys. Rev. B42, 37-42.

Randall, C.R., Shu, Lijin, Chiuo, Yu-Min, Hagen, K.S., Ito, M., Kitajima, N., Lachicotte, R.J., ZANG, YAN \& Que, L. (1995): X-ray absorption pre-edge studies of high-spin iron(II) complexes. Inorg. Chem. 34, 1036-1039.

Roe, A.L., Schneider, D.J., MAYer, R.J., Pyrz, J.W., Widom, J. \& QUE, L., JR. (1984): X-ray absorption spectroscopy of iron-tyrosinate proteins. J. Am. Chem. Soc. 106, 1676-1681.

Shulman, R.G., Yafet, Y., Eisenberger, P. \& Blumberg, W.E. (1976): Observation and interpretation of $\mathrm{x}$-ray absorption edges in iron compounds and proteins. Proc. Nat. Acad. Sci. 73, 1384-1388.

STÖHR, J. (1992): NEXAFS Spectroscopy. Springer-Verlag, Berlin, Germany.

Tombolini, F., Brigatti, M.F., Marcelli, A., Cibin, G., Mottana, A. \& GiUli, G. (2002): Local and average Fe distribution in trioctahedral micas: analysis of $\mathrm{Fe} K$-edge XANES spectra in the phlogopite-annite and phlogopitetetra-ferriphogopite joins on the basis of single-crystal XRD refinements. Eur. J. Mineral. 14, 1075-1085.

Westre, T.E., Kennepohl, P., DeWitt, J.G., Hedman, B., Hodgson, K.O. \& Solomon, E.I. (1997): A multiplet analysis of $\mathrm{Fe} \mathrm{K}$-edge $1 \mathrm{~s} \rightarrow 3 \mathrm{~d}$ pre-edge features of iron complexes. J. Am. Chem. Soc. 119, 6297-6314.

Wilke, M., Farges, F., Petit, P.-E., Brown, G.E., Jr. \& Martin, F. (2001): Oxidation state and coordination of Fe in minerals: an Fe K-XANES spectroscopic study. Am. Mineral. 86, 714-730.

Received December 22, 2001, revised manuscript accepted August 6, 2002. 